\title{
How to kill a tree: empirical mortality models for 18 species and their performance in a dynamic forest model
}

\author{
Lisa Hülsmann, ${ }^{1,2,3,5}$ Harald Bugmann, ${ }^{2}$ Maxime Cailleret, ${ }^{2,4}$ and Peter Brang ${ }^{1}$ \\ ${ }^{1}$ Forest Resources and Management, WSL Swiss Federal Institute for Forest, Snow and Landscape Research, \\ Zürcherstrasse 111, 8903 Birmensdorf, Switzerland \\ ${ }^{2}$ Forest Ecology, Institute of Terrestrial Ecosystems, ETH Zurich, Universitätstrasse 16, 8092 Zürich, Switzerland \\ ${ }^{3}$ Theoretical Ecology, University of Regensburg, Universitätsstraße 31, 93053 Regensburg, Germany \\ ${ }^{4}$ Forest Dynamics, WSL Swiss Federal Institute for Forest, Snow and Landscape Research, Zürcherstrasse 111, \\ 8903 Birmensdorf, Switzerland
}

\begin{abstract}
Dynamic Vegetation Models (DVMs) are designed to be suitable for simulating forest succession and species range dynamics under current and future conditions based on mathematical representations of the three key processes regeneration, growth, and mortality. However, mortality formulations in DVMs are typically coarse and often lack an empirical basis, which increases the uncertainty of projections of future forest dynamics and hinders their use for developing adaptation strategies to climate change. Thus, sound tree mortality models are highly needed. We developed parsimonious, species-specific mortality models for 18 European tree species using $>90,000$ records from inventories in Swiss and German strict forest reserves along a considerable environmental gradient. We comprehensively evaluated model performance and incorporated the new mortality functions in the dynamic forest model ForClim. Tree mortality was successfully predicted by tree size and growth. Only a few species required additional covariates in their final model to consider aspects of stand structure or climate. The relationships between mortality and its predictors reflect the indirect influences of resource availability and tree vitality, which are further shaped by species-specific attributes such as maximum longevity and shade tolerance. Considering that the behavior of the models was biologically meaningful, and that their performance was reasonably high and not impacted by changes in the sampling design, we suggest that the mortality algorithms developed here are suitable for implementation and evaluation in DVMs. In the DVM ForClim, the new mortality functions resulted in simulations of stand basal area and species composition that were generally close to historical observations. However, ForClim performance was poorer than when using the original, coarse mortality formulation. The difficulties of simulating stand structure and species composition, which were most evident for Fagus sylvatica L. and in long-term simulations, resulted from feedbacks between simulated growth and mortality as well as from extrapolation to very small and very large trees. Growth and mortality processes and their species-specific differences should thus be revisited jointly, with a particular focus on small and very large trees in relation to their shade tolerance.
\end{abstract}

Key words: dynamic vegetation models; empirical mortality models; European tree species; forest inventory data; forest reserves; generalized logistic regression; individual tree mortality; tree growth.

\section{INTRODUCTION}

Tree mortality, one of the key demographic processes that shape forest ecosystems, has significant short- and long-term implications for a wide range of forest ecosystem services (Van Mantgem et al. 2009, Millar and Stephenson 2015). Management for ecosystem services therefore requires a good understanding of tree death and of its determinants, in particular since droughtinduced dieback and other mortality hazards are likely to increase in response to future climate change (Allen

Manuscript received 8 March 2017; revised 8 August 2017; accepted 19 October 2017. Corresponding Editor: David S. Schimel.

${ }^{5}$ E-mail: lisa.huelsmann@ur.de et al. 2010, Steinkamp et al. 2015). Tree mortality is a highly complex and multifactorial process, and the scientific community still faces difficulties to understand the underlying mechanisms (Sala et al. 2010) and predict mortality from the individual to the regional level (Weiskittel et al. 2011, Adams et al. 2013, McDowell et al. 2013, Meir et al. 2015).

This difficulty has implications for predictive mortality functions as an essential component of forest simulation models, which are used for short-term forest planning (growth-and-yield models; Hasenauer 2006) and for assessing the long-term consequences of climate change (Dynamic Vegetation Models DVM; Bugmann 2001, Smith et al. 2001, Friend et al. 2014). While much effort has been devoted to accurately predicting tree growth, mortality formulations in DVMs are typically 
coarse and usually lack an empirical basis (Loehle and LeBlanc 1996, Keane et al. 2001) or robust mechanistic foundation (Allen et al. 2015). The poor representation of tree mortality in DVMs has critical consequences for the accuracy of their predictions, and thus for the reliability of their projections (Keane et al. 2001, Reyer et al. 2015), which may impede the timely initiation of measures that maintain ecosystem services (De Groot et al. 2002, Temperli et al. 2012).

Besides theoretical ("data-free") and physiological process-based approaches (cf. Wunder et al. 2006, Weiskittel et al. 2011, Meir et al. 2015 for respective advantages and drawbacks), empirical mortality models have been suggested as a valid and pragmatic alternative (Adams et al. 2013). Such empirical mortality models are not only highly valuable for the reliable simulation of future forest dynamics, but also to improve our understanding of the mortality process (Cailleret et al. 2016). Among other approaches, tree size and radial stem growth can be used as predictors of tree death (Cailleret et al. 2017, Hülsmann et al. 2017), which is supported by the assumption that the dimensions of a tree, typically expressed via its stem diameter, are a proxy for the access to resources and constraints on the hydraulic system (Grote et al. 2016), and that radial growth provides an indication of individual tree vitality (Harcombe 1987, Dobbertin 2005).

Growth-based mortality models have been fitted using forest inventory (Ruiz-Benito et al. 2013) or dendrochronological data (Gillner et al. 2013) and a variety of methodological approaches (Hawkes 2000, Weiskittel et al. 2011, Cailleret et al. 2016). However, most of them (1) do not adequately consider species differences for a wide range of species, (2) are not sensitive to the variation in climate and site conditions, and (3) have not been implemented in DVMs and validated in this context (cf. Larocque et al. 2011, Bircher et al. 2015). The obstacles to achieve this arise from the fact that mortality of individuals having outgrown the seedling stage is rare and highly variable in space and time (Eid and Tuhus 2001), and there is a general scarcity of data for describing long-term processes (Bugmann 1996b, Hawkes 2000).

In DVMs, tree regeneration, growth, and mortality are simulated for individual tree species or Plant Functional Types (PFTs; Bugmann 1996a, Wullschleger et al. 2014). By grouping species with similar ecological characteristics to PFTs, mortality models can be calibrated and validated even for rare species. Yet, modeling approaches are mostly limited to one or few species (Holzwarth et al. 2013, Neuner et al. 2015, but see Wunder et al. 2008). Thus, there is no comprehensive evidence of how life history traits such as shade tolerance and longevity (Bugmann 1994) determine the mortality patterns of tree species, and that PFTs are a useful and robust concept for mortality predictions.

Moreover, only few studies have accounted for the spatial and temporal variability in size-mortality and growth-mortality relationships (Wunder et al. 2008, Dietze and Moorcroft 2011) by including additional covariates in mortality models (but see Condés and Del Río 2015). Climate or stand characteristics may be required as driving factors of mortality under conditions of drought or high competition, since they are only partly reflected in size or growth variables (Rowland et al. 2015). However, data sets with a representative sampling along major environmental gradients and over long time periods that allow for a systematic analysis of environmental influences on the relationship between tree size, growth, and mortality are rare.

To verify the suitability of growth-based empirical mortality functions for DVMs, their predictive performance, i.e., the accuracy of a model when applied to new data, should be evaluated using cross-validation approaches or by validation with independent external data (cf. Hülsmann et al. 2016). Subsequently, such mortality models should be incorporated in DVMs, a step that is made only rarely (but see Wyckoff and Clark 2002, Wernsdörfer et al. 2008, Larocque et al. 2011, Bircher et al. 2015). Thus, a comprehensive and sound assessment of empirical mortality models in DVMs is still lacking, and it remains unclear whether more empiricism in mortality modeling would actually advance the quality of simulations from DVMs.

Thus, the overall objectives of this study were to develop parsimonious mortality models for a large set of European tree species, to comprehensively evaluate their performance, and to incorporate them in a specific DVM (ForClim; cf. Bugmann 1996b). To this end, we used extensive inventory data from strict forest reserves, i.e., areas without forest management, in Switzerland and Germany along a large environmental gradient. We followed the approach of model calibration and evaluation that was established and tested for Fagus sylvatica L. in Hülsmann et al. (2016). Specifically, we addressed three main questions: (1) Can life history traits such as maximum longevity and shade tolerance be used to group tree species into meaningful PFTs that account for species differences in mortality? (2) How successful are mortality models that are based on size and growth alone compared to models that include further climate or stand characteristics in accurately predicting tree mortality? (3) How do the new mortality functions perform when embedded in a DVM?

\section{Material and Methods}

\section{Study areas and inventory data}

We used inventory data from 54 strict forest reserves in Switzerland and Lower Saxony/Germany to develop the mortality models (cf. Meyer et al. 2006, 2015, Brang et al. 2011). Measurements had been conducted repeatedly on up to 14 permanent plots per reserve for up to $60 \mathrm{yr}$ with remeasurement intervals of 4-27 yr. The permanent plots vary in size between 0.03 and 3.47 ha. The inventories provide diameter measurements at breast height $(\mathrm{DBH})$ and information on the species and status (alive or dead) of trees with $\mathrm{DBH} \geq 4 \mathrm{~cm}$ for 
Switzerland and $\geq 7 \mathrm{~cm}$ for Germany. As ForClim does not explicitly simulate natural large-scale disturbances, only plots without substantial fire or bark beetle events at the stand scale were used to derive the mortality models. To this end, we excluded three permanent plots where at least $80 \%$ of the trees died during an interval of $10 \mathrm{yr}$, and mortality could be clearly assigned to a disturbance agent. Mortality in the remaining stands was rather low, with a mean annual mortality rate of $1.5 \%$ and strong variation between plots from $0 \%$ to $6.5 \%$ (assessed for trees of all species with $\mathrm{DBH} \geq 7 \mathrm{~cm}$ ).

We only used data from permanent plots with at least 20 trees per species to obtain reliable plot-level mortality rates even for species with low mortality rates (about 5\% during $10 \mathrm{yr}$ ), and selected tree species occurring on at least 10 plots to cover sufficient ecological gradients. This led to a data set of 197 permanent plots and 18 tree or shrub species: Abies alba Mill., Acer campestre L., Acer pseudoplatanus L., Alnus incana Moench., Betula pendula Roth, Carpinus betulus L., Cornus mas L., Corylus avellana L., Fagus sylvatica L., Fraxinus excelsior L., Picea abies (L.) Karst, Pinus mugo Turra, Pinus sylvestris L., Quercus pubescens Willd., Quercus spp. (Q. petraea Liebl. and Q. robur L.; not properly differentiated in the Swiss inventories), Sorbus aria Crantz, Tilia cordata Mill., and Ulmus glabra Huds. (Table 1).

\section{Mortality information and tree characteristics}

We considered tree size and growth as key indicators for mortality risk (Monserud 1976). Radial stem growth between the first and second inventory and DBH (mm) at the second inventory were used to predict tree status (alive or dead) at the third inventory. To this end, the annual relative basal area increment (relBAI $;$; cf. Bigler and Bugmann 2004) was calculated as the compound annual growth rate of the trees' basal area $\left(\mathrm{BA}_{i}\right)$ using

$$
\operatorname{relBAI} I_{i}=\left(\frac{\mathrm{BA}_{i, 2 n d}}{\mathrm{BA}_{i, 1 s t}}\right)^{\frac{1}{\Delta t}}-1
$$

with $\Delta t$ denoting the number of years of the growth period. Several sets of three inventories per tree were used if more than three inventories were available. Thus, 26.5\% of the trees appeared more than once in the data set (for verification cf. Hülsmann et al. 2016).

To improve the relationship between the explanatory variables and mortality, suitable transformations were applied (cf. Mosteller and Tukey 1977), i.e., $\ln (\mathrm{DBH})$ and $\log _{10}(\mathrm{relBAI})$. The latter is a modified transformation based on the common logarithm that is applicable even to those $8.8 \%$ of the records with relBAI $=0$ (Stahel 2015; cf. Appendix S2).

\section{Climate and stand characteristics}

We included additional climate and stand characteristics in the mortality models to address spatial and temporal differences in mortality rates between permanent plots and inventories that cannot be explained by changes in growth rates alone (cf. Table S1, see Appendix S1 for all additional tables and figures). To this end, mean annual precipitation sum $(P)$ and mean annual air temperature $(\mathrm{mT})$ were calculated between the second and the third inventory (for their derivation cf. Appendix S2).

TABLE 1. Number of records per tree species.

\begin{tabular}{|c|c|c|c|c|c|c|}
\hline Species & Total & Germany & Switzerland & Dead & Reserves & Permanent plots \\
\hline Abies alba & 7,140 & 0 & 7,140 & 1,147 & 7 & 31 \\
\hline Acer campestre & 1,183 & 0 & 1,183 & 256 & 5 & 19 \\
\hline Acer pseudoplatanus & 1,399 & 24 & 1,375 & 255 & 12 & 26 \\
\hline Alnus incana & 1,252 & 0 & 1,252 & 734 & 5 & 11 \\
\hline Betula pendula & 1,847 & 300 & 1,547 & 723 & 7 & 14 \\
\hline Carpinus betulus & 5,789 & 1,637 & 4,152 & 1,283 & 19 & 28 \\
\hline Cornus mas & 1,123 & 0 & 1,123 & 215 & 1 & 10 \\
\hline Corylus avellana & 1,427 & 0 & 1,427 & 739 & 8 & 14 \\
\hline Fagus sylvatica & 26,645 & 6,899 & 19,746 & 4,018 & 40 & 118 \\
\hline Fraxinus excelsior & 7,645 & 142 & 7,503 & 1,715 & 19 & 52 \\
\hline Picea abies & 12,965 & 458 & 12,507 & 2,209 & 20 & 59 \\
\hline Pinus mugo & 7,376 & 0 & 7,376 & 1,250 & 4 & 21 \\
\hline Pinus sylvestris & 2,925 & 317 & 2,608 & 519 & 10 & 24 \\
\hline Quercus pubescens & 2,968 & 0 & 2,968 & 429 & 2 & 15 \\
\hline Quercus spp. & 7,250 & 832 & 6,418 & 1,536 & 22 & 48 \\
\hline Sorbus aria & 1,546 & 0 & 1,546 & 492 & 8 & 23 \\
\hline Tilia cordata & 1,911 & 0 & 1,911 & 344 & 8 & 16 \\
\hline Ulmus glabra & 631 & 20 & 611 & 137 & 4 & 11 \\
\hline All & 93,022 & 10,629 & 82,393 & 18,001 & 54 & 197 \\
\hline
\end{tabular}

Notes: Numbers are given for the total data set, per country and for those that resulted in tree death. Additionally, the number of reserves and permanent plots that are covered in the data of each species are indicated. Quercus spp. refers to both $Q$. petraea and Q. robur. 
As a proxy for stand age and structural complexity, the mean and the interquartile range of $\mathrm{DBH}$ were calculated at the permanent plot level (mDBH, iqrDBH). To account for stand density, basal area (BA) and the number of trees $(N)$ per hectare were considered. These stand characteristics were calculated for the second inventory based on all living trees $\geq 7 \mathrm{~cm}$. We did not further expand the set of climate and stand characteristics considered to keep the models simple and thus also applicable in DVMs.

\section{Mortality models}

Generalized logistic regression (Monserud 1976, Weiskittel et al. 2011, Yang and Huang 2013) was used to model mortality probability. This was necessary to account for the unequal remeasurement intervals in the inventory data. The annual mortality probability of tree $i\left(p_{i, \Delta t}=1\right)$ was defined as

$$
p_{i, \Delta t=1}=\operatorname{logit}^{-1}\left(X_{i} \beta\right)=\frac{\exp \left(X_{i} \beta\right)}{1+\exp \left(X_{i} \beta\right)}
$$

with $X_{i}$ denoting the design matrix of the linear predictor and $\beta$ the respective parameter vector. The annual probability was scaled to the length of the respective mortality period of $\Delta t$ years using

$$
p_{i, \Delta t}=1-\left(1-p_{i, \Delta t=1}\right)^{\Delta t}
$$

and then fitted against the observed status of the tree $\left(y_{i}\right.$; $1=$ dead, $0=$ alive) using maximum-likelihood estimation for the parameters of $\beta$. Standard errors, confidence intervals, and $P$ values of the parameter estimates were derived using the Fisher information based on the Hessian matrix (cf. Hülsmann et al. 2016).

\section{Model selection and performance criteria}

In a first step, the most promising climate or stand characteristic and its most suitable transformation (log, square root, or none) were identified for each species. To this end, covariates were included in highly flexible models to capture linear, non-linear, and interacting influences of $\ln (\mathrm{DBH})$ and $\log _{10}($ relBAI) on mortality (cf. Table 2 , Formula $\mathrm{C} 12$ with different transformations of the climate and stand characteristics). We selected the covariate that resulted in the smallest Brier Score (BS). BS corresponds to the mean squared error of the model defined as

$$
\mathrm{BS}=\frac{1}{n} \sum_{i=1}^{n}\left(p_{i, \Delta t}-y_{i}\right)^{2}
$$

and ranges between 0 and 1 , with low values indicating good model calibration and discrimination, i.e., correct mortality rates and attribution of dead/alive status (cf. Harrell 2015). BS does, however, not allow for the comparison of models based on different data sets since it depends on the overall mortality rate that varies between species (Steyerberg et al. 2010).

In a second step, the final model was selected from a large set of model formulae (cf. Table 2) with varying complexity and flexibility that are based on the terms ln $(\mathrm{DBH}), \log _{10}(\mathrm{relBAI})$, their interaction and the respective quadratic terms (Formulae 1-12). These models were analyzed without an additional covariate (Formulae A1-12),

\begin{tabular}{|c|c|c|c|c|}
\hline \multirow[b]{2}{*}{ Number } & \multicolumn{4}{|c|}{ Use of additional climate or stand characteristics } \\
\hline & Formula & A & $\mathrm{B}$ & $\mathrm{C}$ \\
\hline 1 & $\ln (\mathrm{DBH})$ & 1 & 11 & \\
\hline 2 & $\ln (\mathrm{DBH})+(\ln (\mathrm{DBH}))^{2}$ & 2 & 12 & \\
\hline 3 & $\log _{10}($ relBAI $)$ & 1 & 11 & 21 \\
\hline 4 & $\log _{10}(\operatorname{relBAI})+\left(\log _{10}(\operatorname{relBAI})\right)^{2}$ & 2 & 12 & 22 \\
\hline 5 & $\ln (\mathrm{DBH})+\log _{10}(\mathrm{relBAI})$ & 3 & 13 & 23 \\
\hline 6 & $\ln (\mathrm{DBH})+(\ln (\mathrm{DBH}))^{2}+\log _{10}(\operatorname{relBAI})$ & 4 & 14 & 24 \\
\hline 7 & $\ln (\mathrm{DBH})+\log _{10}($ relBAI $)+\left(\log _{10}(\text { relBAI })\right)^{2}$ & 4 & 14 & 24 \\
\hline 8 & $\ln (\mathrm{DBH})+(\ln (\mathrm{DBH}))^{2}+\log _{10}(\operatorname{relBAI})+\left(\log _{10}(\operatorname{relBAI})\right)^{2}$ & 5 & 15 & 25 \\
\hline 9 & $\ln (\mathrm{DBH}) \times \log _{10}(\mathrm{relBAI})$ & 6 & 16 & 26 \\
\hline 10 & $\ln (\mathrm{DBH}) \times \log _{10}($ relBAI $)+(\ln (\mathrm{DBH}))^{2}$ & 7 & 17 & 27 \\
\hline 11 & $\ln (\mathrm{DBH}) \times \log _{10}(\operatorname{relBAI})+\left(\log _{10}(\operatorname{relBAI})\right)^{2}$ & 7 & 17 & 27 \\
\hline 12 & $\ln (\mathrm{DBH}) \times \log _{10}(\mathrm{relBAI})+(\ln (\mathrm{DBH}))^{2}+\left(\log _{10}(\mathrm{relBAI})\right)^{2}$ & 8 & 18 & 28 \\
\hline
\end{tabular}
with the most promising climate or stand characteristic

TABLE 2. Model formulae considered during model selection and their degree of complexity.

Notes: Model numbers 1-12 in the first column refer to formulae with increasing flexibility of the influence of the tree covariates diameter at breast height (DBH, mm, log-transformed) and annual relative basal area increment (relBAI, dimensionless, $\log _{10^{-}}$ transformed). The letters A-C refer to the use of additional climate or stand characteristics: A, without an additional characteristic; $\mathrm{B}$, with an additional characteristic; $\mathrm{C}$, with an additional characteristic and its interaction with $\log _{10}$ (relBAI). The numbers of 1-28 in columns A-C indicate increasing complexity of the formulae and were used to select the most parsimonious models during 10 -fold cross-validation (cf. Appendix S2). For instance, model B3 in line 3 and column B stands for the formula " $\log _{10}(\mathrm{relBAI})$ " plus an additional climate or stand characteristic and has a complexity of 11 . The complexity of a model was assigned considering the number of predictors and their flexibility (quadratic terms, interactions). Note that the additional characteristic was selected separately for each species (cf. Appendix S1: Table S4). 
(B1-12), and in interaction with $\log _{10}$ (relBAI) (C3-12). To this end, we calculated BS in repeated 10-fold cross-validation and applied the "one standard error rule" to avoid overfitting and overly complex models (cf. Appendix S2 for details; Breiman et al. 1984, Hastie et al. 2001). For models that included an additional climate or stand characteristic, an alternative model without that covariate was derived to compare its performance with the respective full model. These were selected by applying the "one standard error rule" to Formulae A1-12 only.

Several performance criteria were reported to take into account that calibration and discrimination are not necessarily correlated (Bravo-Oviedo et al. 2006). In addition to BS, the Area under the receiver operating characteristic Curve (AUC) was calculated, which is a threshold-independent measure of classification accuracy. Following Hosmer and Lemeshow (2000), the discriminative ability is rated as acceptable $(0.7 \leq \mathrm{AUC}<0.8)$, excellent $(0.8 \leq$ AUC $<0.9)$, or outstanding (AUC $\geq 0.9$ ).

Since all data were used for model development, no external validation of the models using independent data could be carried out. However, to correct for overfitting and assess the predictive behavior in external application, i.e., when applied to new data from the same domain, BS and AUC from cross-validation were reported (cf. Appendix S2). Furthermore, AUC was calculated for diameter classes to assess the calibration success of the models with respect to tree size.

Commonly, performance criteria used in mortality studies do not convey an intuitive expectation of the predictive behavior of mortality models at the level of forest stands. Therefore, we selected an additional performance criterion that facilitates the evaluation of model performance with respect to the application in DVMs. We defined the prediction bias $p_{\text {bias }}$ as the difference of the mean predicted annual mortality probability (simulated mortality) $\bar{p}_{\Delta t=1}$ and the mean annual mortality rate (observed mortality) $\bar{y}_{\Delta t=1}$ calculated at the level of single inventories of permanent plots (cf. Appendix S2) and reported the mean absolute deviation (mad) of $p_{\text {bias. }}$ This allowed us to quantify the variation in prediction accuracy, i.e., how well the models can deal with the high variability of mortality rates and patterns in space and time (Wunder et al. 2008, Dietze and Moorcroft 2011). Observed variability and mad $p_{\text {bias }}$ increase with increasing mortality rates. Therefore, we additionally calculated the respective relative value ( $\mathrm{rmad} p_{\text {bias }}$ ), i.e., the ratio of $\operatorname{mad} p_{\text {bias }}$ and the observed annual mortality rate $\bar{y}_{\Delta t=1}$. Both values were used to evaluate the models with respect to their ability to predict correct mortality rates in space and time.

Model calibration and evaluation was performed with $\mathrm{R}$ ( $\mathrm{R}$ Core Team 2015). The function $\log 10($ ) from the package regr0 (Version 1.0-4/r46, 2015) was used for the relBAI transformation. The function optim() and the BFGS method were applied for maximum-likelihood estimation. AUC was calculated using a modified version of the auc() function from the package SDMTools (Version
$1.1-221,2014)$ to allow for values below 0.5 , which is necessary to calculate AUC in cross-validation.

\section{Implementation of inventory-based mortality models in ForClim}

Model description.-To examine the performance and behavior of the new mortality functions in DVMs, we used the climate-sensitive forest gap model ForClim, which simulates the dynamics of forest stands on short and long time scales (Bugmann 1996b). Establishment, growth and mortality for cohorts of individual trees are simulated on independent patches $\left(\sim 800 \mathrm{~m}^{2}\right)$ at an annual resolution based on species-specific parameters (e.g., shade and drought tolerance), environmental conditions (light availability, temperature, soil nitrogen, and water availability), and tree characteristics (cf. Bugmann 1996b, Didion et al. 2011, Rasche et al. 2012).

In the latest model version, ForClim 3.3 (Mina et al. 2015), tree mortality is modeled as a combination of a constant 'background' mortality that depends on the species-specific maximum age and a stress-induced mortality that is activated if the annual diameter increment is lower than an absolute or relative growth threshold (3 $\mathrm{mm}$ or $10 \%$ of the species-specific maximum growth rate at a given tree size, respectively) for more than two consecutive years. Mortality is modeled individually for each tree of a cohort based on a stochastic approach that results in tree death if a uniformly distributed random number between 0 and 1 is below the annual mortality probability. A more detailed description of the mortality function is provided in Bircher et al. (2015).

This mortality formulation was replaced by the new inventory-based models (IM) without environmental covariates, i.e., alternative models, based on tree size and growth only. The models were implemented following two approaches: (1) with mean parameter estimates (IM_mean) and (2) by randomly sampling the parameters using their mean and standard error to account for the uncertainty in model estimates (IM_sd, assuming a normal distribution of the parameters).

The mortality functions were applied to all trees irrespective of their DBH although this led to extrapolation at least for the small trees (initial DBH of trees in ForClim is $1.27 \mathrm{~cm}$ whereas the calipering threshold in the inventories is $4 \mathrm{~cm}$ or more). Since no mortality function could be developed for some species in the validation data, we used the models from species of the same genus: the model of Acer pseudoplatanus for A. platanoides, Alnus incana for A. glutinosa and A. viridis, Sorbus aria for S. aucuparia, and Tilia cordata for T. platyphyllos. Simulation results for these species were jointly reported (e.g., Tilia spp.). Species for which no mortality model could be developed and that were present in minor abundance were excluded from the simulations (e.g., Populus nigra, Taxus baccata).

Simulation setup and model validation.-We ran shortand long-term simulations to assess the performance 
and behavior of the two new mortality functions (IM_mean, IM_sd) and to compare them with the original model version (ForClim 3.3), as follows.

Short-term simulations. - To validate the new mortality functions in ForClim, we simulated historical forest dynamics based on past climate data (cf. Appendix S2) and compared the results against inventory measurements. To this end, permanent plots were selected from the Swiss forest reserves according to the following criteria: (1) inventory data should cover at least a period of $35 \mathrm{yr},(2)$ plot size had to exceed 0.2 ha to ensure a representative structure and composition of the forest, and (3) recent dynamics had to be unaffected by severe natural disturbances, which are not accounted for in the model. We ended up with 28 permanent plots located in 13 forest reserves (Appendix S1: Table S2) that were all part of the calibration data set. ForClim was initialized with single-tree data (species, DBH) from the first available inventory of each permanent plot. As spatial information about tree positions on the plots was not available, trees were allocated randomly and evenly to an initial set of patches, each with a size of $800 \mathrm{~m}^{2}$ (Wehrli et al. 2005). Depending on the ratio of permanent plot area and patch size (Appendix S1: Table S2), this resulted in the direct initialization of 2-44 patches. To average over the stochasticity across patches, the initial set of patches was replicated to 200. For evaluating the goodness-of-fit of the historical runs, we compared simulated and measured stand- and species-specific BA at the last inventory and the cumulative number of dead trees $\left(N_{\text {dead }}\right)$ over the whole period. The root mean square error (RMSE) as well as the relative bias (rbias) were reported for both criteria separately per species and permanent plot.

Long-term simulations. - As model validation is constrained by the short length of the empirical data series, we also simulated Potential Natural Vegetation (PNV), i.e., the species composition expected in a pseudo-equilibrium state in the absence of anthropogenic influences (Ellenberg 2009), at seven sites along a well-studied environmental gradient in Switzerland (cf. Bugmann and Solomon 2000). Note that we could not apply the models at the sites Grande Dixence and Bever, since we were not able to calibrate a mortality model for Pinus cembra L. Starting from bare ground, forest dynamics were simulated for 1,500 yr without any large-scale disturbances, and forest structure and composition at the end of the simulation were examined qualitatively for their plausibility (Rasche et al. 2012).

\section{RESUlts}

\section{Size and growth influences on mortality}

Formulae of the final models varied between tree species with respect to the flexibility of the covariates $\mathrm{DBH}$ and relBAI (Appendix S1: Table S3). Nevertheless, all models except for those of Cornus mas, Pinus mugo, and Ulmus glabra, which were based on tree growth alone (Formulae 3 and 4), included both explanatory variables. Most common was Formula 7 with medium complexity and the terms $\ln (\mathrm{DBH})+\log _{10}(\mathrm{relBAI})+\left(\log _{10}(\mathrm{relBAI})\right)^{2}$, which was selected for 10 species. Mortality of three species was best predicted using Formula 5, including only $\mathrm{DBH}$ and relBAI without any quadratic term or interaction. Only for Tilia cordata (Formula 9) and Fraxinus excelsior (Formula 11), models were more complex and included also the interaction between $\ln (\mathrm{DBH})$ and $\log _{10}($ relBAI).

In spite of the different model formulae, the overall pattern of simulated mortality with respect to the main predictors was very similar for most species, i.e., mortality risk decreased with increasing tree size and growth resulting in reverse $\mathrm{J}$-shaped mortality over DBH and relBAI (Fig. 1). However, the models differed concerning (1) the respective influence of size and growth as characterized by the steepness of the slope of mortality over DBH and relBAI, and (2) the overall level of mortality probabilities. Based on these two criteria, each species could be visually assigned to one of four main patterns: (1) low overall mortality and a slight effect of DBH and relBAI (Abies alba, Cornus mas, Fagus sylvatica, Picea abies, Pinus mugo, Tilia cordata and Ulmus glabra), (2) high overall mortality, also in large trees, and a strong growth influence on mortality (Alnus incana, Betula pendula, Corylus avellana and Sorbus aria), (3) strong impacts of DBH and relBAI on mortality (Acer pseudoplatanus, Pinus sylvestris, Quercus pubescens and Quercus spp.), and (4) intermediate impacts of DBH and relBAI on mortality (Acer campestre, Carpinus betulus and Fraxinus excelsior).

None of the species-specific models included a quadratic term for DBH, which would suggest a U-shaped mortality pattern, i.e., higher mortality for both small and larger trees. The quadratic term of $\log _{10}$ (relBAI), which was included in 12 of the 18 final models, dominantly resulted in a pronounced decrease of mortality probability

FIG. 1. Prediction maps of 10 -yr mortality probability as a function of diameter at breast height (DBH, mm) and relative basal area increment (relBAI). In accordance with the variable transformations applied in the models, logarithmic scales are used for plotting, i.e., natural logarithm for DBH and the base 10 logarithm for relBAI (cf. log10 transformation; Stahel 2015). The interval $\Delta t=10 \mathrm{yr}$ for the mortality probability was selected to increase the contrast of the typically very low annual mortality probabilities. Predictions of models that included an additional climate or stand characteristic are shown for the additional covariate fixed at its mean value as indicated in the plot. Additional covariates are BA, stand basal area $\left(\mathrm{m}^{2} / \mathrm{ha}\right) ; \mathrm{P}$, mean annual precipitation sum $(\mathrm{mm}) ; \mathrm{mDBH}$, arithmetic mean $\mathrm{DBH}(\mathrm{mm}) ; \mathrm{mT}$, mean annual air temperature $\left({ }^{\circ} \mathrm{C}\right)$; or none. Observations of DBH and relBAI are shown with black triangles. No-growth observations are located at the lower limit of the predictive map defined by backtransformed $\log 10(0)$, i.e., 0.0008029 . 


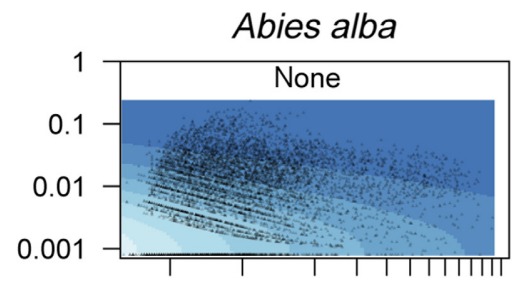

Alnus incana

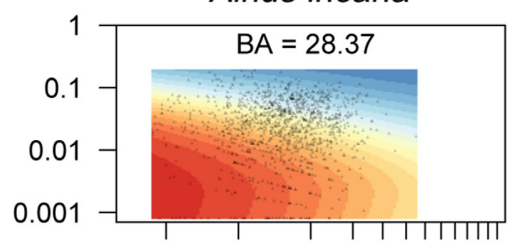

Cornus mas

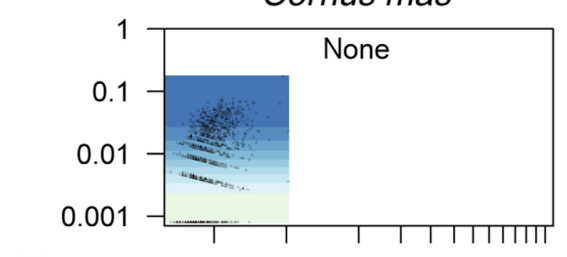

$\underset{\frac{\pi}{\Phi}}{\stackrel{\varpi}{\varrho}}$

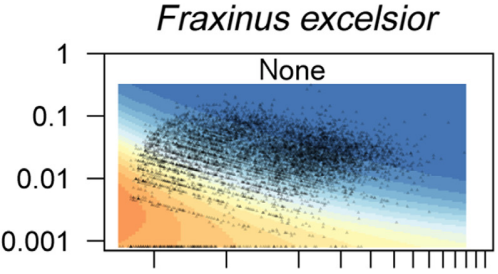

Pinus sylvestris
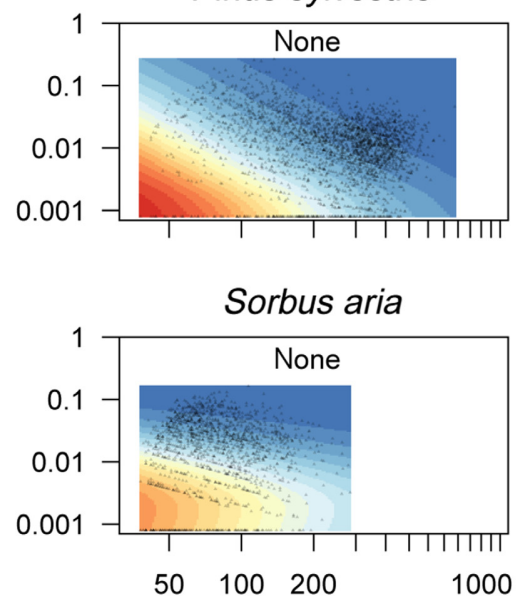

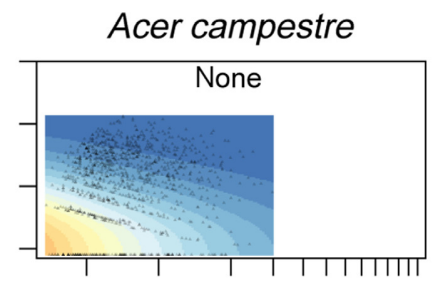

Betula pendula

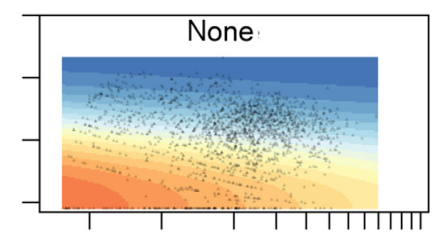

Corylus avellana

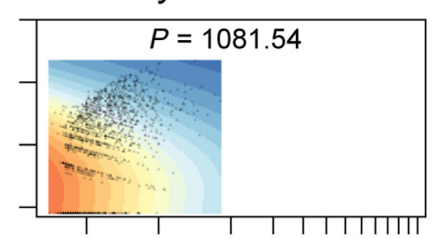

Picea abies

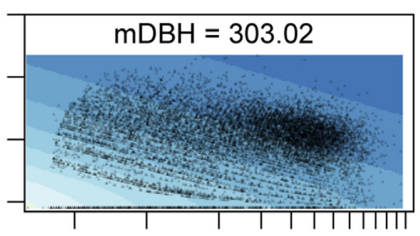

Quercus pubescens

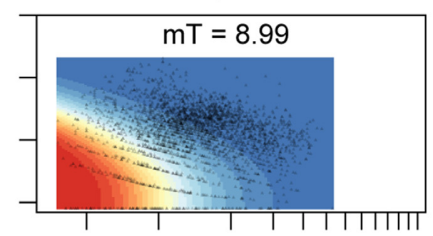

Tilia cordata

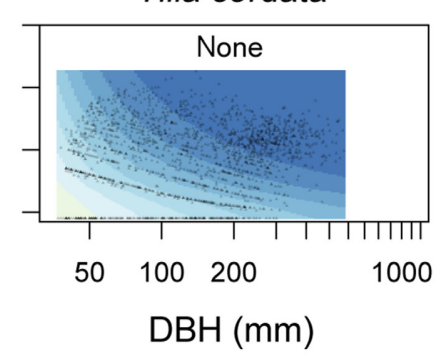

Acer pseudoplatanus

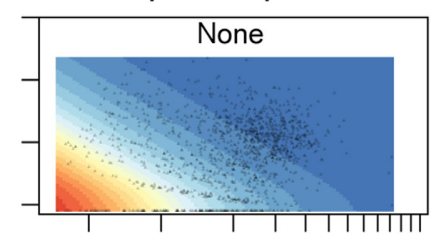

Carpinus betulus

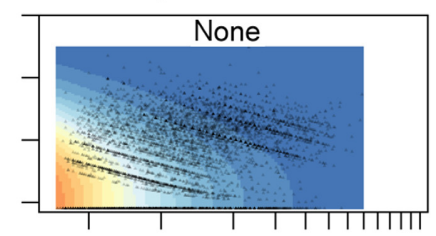

Fagus sylvatica

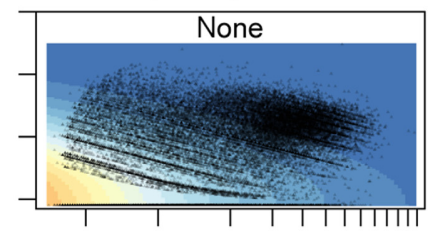

Pinus mugo

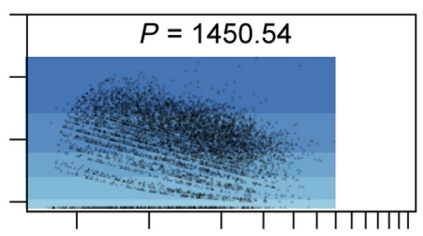

Quercus spp.

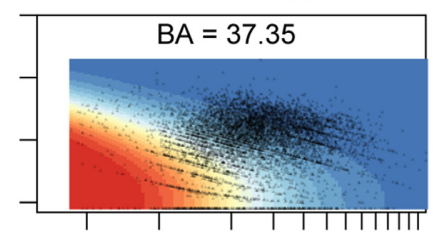

Ulmus glabra

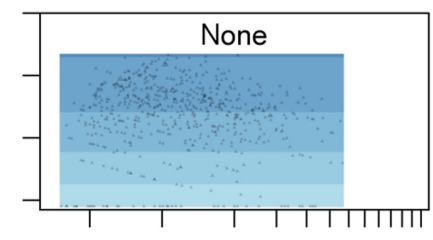

$\begin{array}{llll}50 & 100 \quad 200 \quad 1000\end{array}$

Ten-year mortality probability (\%)

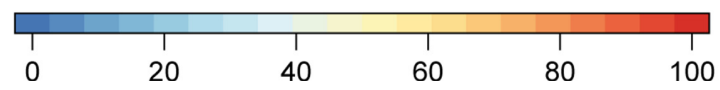


with increasing growth. For Alnus incana, Fraxinus excelsior, and Sorbus aria, the quadratic growth term decreased the predicted mortality probability of trees with very slow growth (relBAI $<0.002$ ), but did not modify the overall positive effect of growth on survival.

\section{Climate and stand influences on mortality}

From the set of the most promising climate or stand characteristics selected for each species (cf. Appendix S1: Table S4), only a few remained in the final models (Appendix S1: Table S3). Additional covariates considerably improved the models of Alnus incana (improved by BA), Corylus avellana $(P)$, Picea abies $(\mathrm{mDBH})$, Pinus mugo (P), Quercus pubescens (mT), and Quercus spp. (BA). The two stand variables (BA and $\mathrm{mDBH}$ ) were positively correlated with mortality (cf. Appendix S1: Fig. S1). The effect of precipitation $(P)$ was inconsistent. At high $P$, mortality probability was lower for Pinus mugo but higher for Corylus avellana. Higher mean temperature (mT) increased mortality of Quercus pubescens.
None of the additional covariates that remained in the models required an interaction term with tree growth. Thus, the general relationship between relBAI and mortality was not altered.

Alternative models without the additional covariate were based on the same or a similar formula as the full model (cf. Appendix S1: Table S5). Thus, they indicate a similar complexity and shape of the relationship between DBH, relBAI, and mortality (cf. Appendix S1: Fig. S2). For Corylus avellana, Picea abies, and Quercus pubescens, a formula with lower flexibility was selected for the alternative model, which resulted in size-independent mortality for Picea abies.

\section{Calibration performance}

Discrimination accuracy (AUC) was high for most species (Table 3). While the ability of the models to correctly identify tree status was acceptable for seven species $(0.7 \leq$ AUC $<0.8)$, it was even excellent for nine species $(0.8 \leq$ AUC $<0.9)$. Only the models of Picea abies

TABLE 3. Performance criteria of the calibrated models.

\begin{tabular}{|c|c|c|c|c|c|c|c|c|c|}
\hline Species & Formula & Covariate & BS & BS CV & AUC & $\begin{array}{c}\text { AUC } \\
\text { CV }\end{array}$ & $\bar{y}_{\Delta t=1}(\%)$ & $\operatorname{mad} p_{\text {bias }}(\%)$ & $\operatorname{rmad} p_{\text {bias }}$ \\
\hline Abies alba & A7 & - & 0.1233 & 0.1235 & 0.721 & 0.720 & 1.3 & 0.7 & 0.53 \\
\hline Acer campestre & A7 & - & 0.1310 & 0.1323 & 0.815 & 0.813 & 2.2 & 1.5 & 0.68 \\
\hline Acer pseudoplatanus & A5 & - & 0.1114 & 0.1121 & 0.847 & 0.846 & 1.7 & 0.8 & 0.48 \\
\hline Alnus incana & B7 & BA & 0.1828 & 0.1843 & 0.790 & 0.788 & 9.1 & 2.7 & 0.30 \\
\hline Alnus incana & A7 & - & 0.1869 & 0.1881 & 0.778 & 0.777 & 9.1 & 4.6 & 0.51 \\
\hline Betula pendula & A7 & - & 0.1878 & 0.1886 & 0.766 & 0.765 & 4.5 & 2.3 & 0.51 \\
\hline Carpinus betulus & A7 & - & 0.1335 & 0.1337 & 0.806 & 0.806 & 2.2 & 1.3 & 0.59 \\
\hline Cornus mas & A4 & - & 0.1270 & 0.1280 & 0.790 & 0.789 & 1.8 & 0.6 & 0.32 \\
\hline Corylus avellana & B7 & $\mathbf{P}$ & 0.2024 & 0.2037 & 0.753 & 0.751 & 6.7 & 1.6 & 0.24 \\
\hline Corylus avellana & A5 & - & 0.2144 & 0.2152 & 0.725 & 0.724 & 6.7 & 3.2 & 0.48 \\
\hline Fagus sylvatica & A7 & - & 0.1032 & 0.1032 & 0.814 & 0.814 & 1.4 & 0.5 & 0.36 \\
\hline Fraxinus excelsior & A11 & - & 0.1326 & 0.1328 & 0.813 & 0.813 & 2.2 & 1.1 & 0.48 \\
\hline Picea abies & B5 & $\mathrm{mDBH}$ & 0.1348 & 0.1349 & 0.659 & 0.658 & 1.5 & 1.1 & 0.72 \\
\hline Picea abies & A3 & - & 0.1371 & 0.1372 & 0.616 & 0.616 & 1.5 & 1.0 & 0.68 \\
\hline Pinus mugo & B3 & $\mathbf{P}$ & 0.1217 & 0.1218 & 0.766 & 0.766 & 1.2 & 0.5 & 0.44 \\
\hline Pinus mugo & A3 & - & 0.1266 & 0.1267 & 0.720 & 0.720 & 1.2 & 1.0 & 0.84 \\
\hline Pinus sylvestris & A5 & - & 0.1128 & 0.1132 & 0.815 & 0.814 & 1.7 & 0.6 & 0.36 \\
\hline Quercus pubescens & B7 & mT & 0.0777 & 0.0782 & 0.892 & 0.891 & 1.6 & 0.4 & 0.22 \\
\hline Quercus pubescens & A5 & - & 0.0840 & 0.0843 & 0.884 & 0.884 & 1.6 & 0.7 & 0.46 \\
\hline Quercus spp. & B7 & BA & 0.1123 & 0.1125 & 0.842 & 0.842 & 2.0 & 1.0 & 0.51 \\
\hline Quercus spp. & A7 & - & 0.1150 & 0.1152 & 0.838 & 0.838 & 2.0 & 1.1 & 0.56 \\
\hline Sorbus aria & A7 & - & 0.1563 & 0.1573 & 0.821 & 0.821 & 3.3 & 1.8 & 0.55 \\
\hline Tilia cordata & A9 & - & 0.1233 & 0.1240 & 0.798 & 0.796 & 1.5 & 1.3 & 0.89 \\
\hline Ulmus glabra & A3 & - & 0.1658 & 0.1672 & 0.616 & 0.614 & 1.8 & 1.0 & 0.53 \\
\hline
\end{tabular}

Notes: For model formulae, refer to Table 2. Brier Score (BS) and Area Under the receiver operating characteristic curve (AUC) were calculated for the entire calibration data set and during repeated 10 -fold cross-validation (CV) to assess the predictive ability of the mortality models. To quantify the variation in prediction accuracy, the mean absolute deviation (mad) of the prediction bias $p_{\text {bias }}$ defined as the difference of the mean predicted annual mortality probability $\bar{p}_{\Delta t=1}$ and the mean annual mortality rate $\bar{y}_{\Delta t=1}$ was calculated at the level of single inventories of permanent plots (cf. Appendix S2). Observed variability and mad $p_{\text {bias }}$ increase with increasing mortality rates. Therefore, we additionally calculated the respective relative value $\left(\mathrm{rmad} p_{\text {bias }}\right)$, i.e., the ratio of mad $p_{\text {bias }}$ and the observed annual mortality rate $\bar{y}_{\Delta t=1}$. Both values were used to evaluate the models with respect to their ability to predict correct mortality rates in space and time. For species for which the final model included an additional covariate (highlighted in boldface type), the performance of the best model without an additional covariate (A1-12) is also given (alternative models). Additional covariates are BA, stand basal area $\left(\mathrm{m}^{2} / \mathrm{ha}\right) ; P$, mean annual precipitation sum $(\mathrm{mm}) ; \mathrm{mDBH}$, arithmetic mean DBH $(\mathrm{mm})$; $\mathrm{mT}$, mean annual air temperature $\left({ }^{\circ} \mathrm{C}\right)$. 
and Ulmus glabra had no discriminative ability. The over-optimism assessed via cross-validation was low for all species, i.e., the relative difference between cross-validation BS and apparent BS was $<1 \%$ of apparent BS, and cross-validation AUC was only $<0.003$ lower than apparent AUC (Table 3).

AUC plotted as a function of DBH revealed that discrimination was not equally successful across tree size (Appendix S1: Fig. S3). Mostly, AUC decreased with increasing DBH, indicating that the models had less or even no discriminative power for larger trees (cf. Acer pseudoplatanus, Fagus sylvatica, Picea abies, Pinus mugo, Quercus pubescens, Quercus spp., and Ulmus glabra). In contrast, an increasing AUC trend with tree size was identified for Cornus mas and Corylus avellana. The models of the remaining species either had the best AUC for medium-sized trees (cf. Acer campestre and Fraxinus excelsior) or achieved a constant discrimination over the considered DBH range.

The variation of the prediction accuracy between sites and inventory periods, assessed as rmad $p_{\text {bias }}$, ranged between 0.22 and 0.89 (Table 3). Fairly large values resulted for Acer campestre, Picea abies, Pinus mugo, and Tilia cordata ( $\mathrm{rmad} p_{\text {bias }} \geq 0.68$ ), while models of Alnus incana, Cornus mas, Corylus avellana, and Quercus pubescens achieved lowest $\mathrm{rmad} p_{\text {bias }}(\leq 0.32)$ and hence the most accurate prediction of mortality rates at the level of single inventories. The underlying values of mad $p_{\text {bias }}$ indicate that the models estimate annual mortality rates at the level of single inventories with an average absolute bias of $0.4-4.6 \%$ per year.

The alternative models that did not include additional covariates had reduced discriminative power, i.e., lower AUC, when compared to the corresponding full model (Table 3). Nevertheless, the reduction in AUC was small $(<0.03$ except for Picea abies and Pinus mugo $)$ and did not change the discriminative ability, as rated following Hosmer and Lemeshow (2000). However, the models' ability to accurately predict mortality rates in space and time was more severely affected when additional covariates were omitted. Models that included an additional covariate typically had a substantially lower rmad $p_{\text {bias }}$ than the alternative models for the respective species. Only for Picea abies was rmad $p_{\text {bias }}$ not reduced by the additional covariate, which was in accordance with the poor discriminative ability of both model formulations of this species.

\section{Implementation of inventory-based mortality models in For Clim}

Short-term simulations.-Compared with forest inventory data, the new model versions ForClim IM_mean and IM_sd performed slightly worse than ForClim 3.3 in predicting stand- and species-specific BA at the end of the historical runs (Fig. 2, Table 4; Appendix S1: Table S6). Overall, the inventory-based models overestimated BA. Although BA of several species was too high, overestimation was particularly driven by Fagus sylvatica (RMSE > $11 \mathrm{~m}^{2} / \mathrm{ha}$, rbias $>30 \%$ ) and occurred especially at permanent plots where this species dominates (e.g., Fürstenhalde and Weidwald; cf. Fig. 2; Appendix S1: Table S6). BA was underestimated by the new mortality functions for Alnus spp., Betula pendula, Corylus avellana, Fraxinus excelsior, and Tilia spp. (cf. Table 4). Accounting for uncertainty in model parameters resulted in pronounced underestimation of BA, so that the IM_mean approach achieved better BA performance than ForClim IM_sd. The reduction of BA caused by the random sampling of the parameters of the mortality formulation was especially strong for Acer campestre, Carpinus betulus, Sorbus spp., and Tilia spp. but negligible in the case of Fagus sylvatica (cf. Fig. 2, Table 4).

In contrast, IM_sd was superior to ForClim 3.3 in predicting accurate numbers of dead trees for most of the species (cf. Table 4), but the performance of ForClim 3.3 in predicting $\mathrm{N}_{\text {dead }}$ was better in the majority of the permanent plots (cf. Appendix S1: Table S6) since most of them were dominated by Fagus sylvatica. For this species, mortality rates were strongly underestimated by both inventory-based mortality functions (cf. Table 4).

Based on the simulation results with the new mortality functions, three main types of disagreement between observed and simulated BA and $\mathrm{N}_{\text {dead }}$ could be distinguished. For their interpretation, the number of observed versus simulated $\mathrm{N}_{\text {dead }}$ as a function of DBH (cf. Appendix S1: Fig. S6) must be considered, as follows.

First, simulated BA for Fagus sylvatica, Pinus mugo, and Pinus sylvestris was overestimated since mortality was considerably underestimated, most markedly for Fagus sylvatica trees with DBH $<20 \mathrm{~cm}$. Second, the opposite was found for Acer campestre, Carpinus betulus, Fraxinus excelsior, and Tilia spp. simulated by IM_sd since too many trees died, in particular between 16 and $40 \mathrm{~cm}$ DBH (e.g., Tariche Haute Côte, Weidwald). Finally, BA and $\mathrm{N}_{\text {dead }}$ were jointly underestimated for several other species including Picea abies, which is the result of considerably underestimated mortality of small trees $(\mathrm{DBH}<8 \mathrm{~cm})$ and overestimated mortality of large trees (e.g., Scatlè). However, the prediction accuracy of trees with large DBH varied among sites. In contrast to mortality patterns in the inventory data, simulated mortality over DBH of Acer pseudoplatanus, Fagus sylvatica, and Picea abies, was not reverse J-shaped but clearly hump-shaped (cf. Appendix S1: Fig. S6).

Long-term simulations.-Species composition and BA predicted after 1,500 yr differed considerably between ForClim 3.3 and ForClim including the new mortality functions. In the center of the Swiss environmental gradient, the dominance of Fagus sylvatica as simulated by ForClim IM_mean and IM_sd was even more evident than in short-term simulations (Fig. 3). High BA of Fagus sylvatica was fostered by trees reaching very large DBH (e.g., $>280 \mathrm{~cm}$ in Bern). At the sites dominated by Fagus sylvatica, Carpinus betulus also established in small numbers, but those trees reached great size and thus contributed strongly to total BA. In comparison, the BA of other 


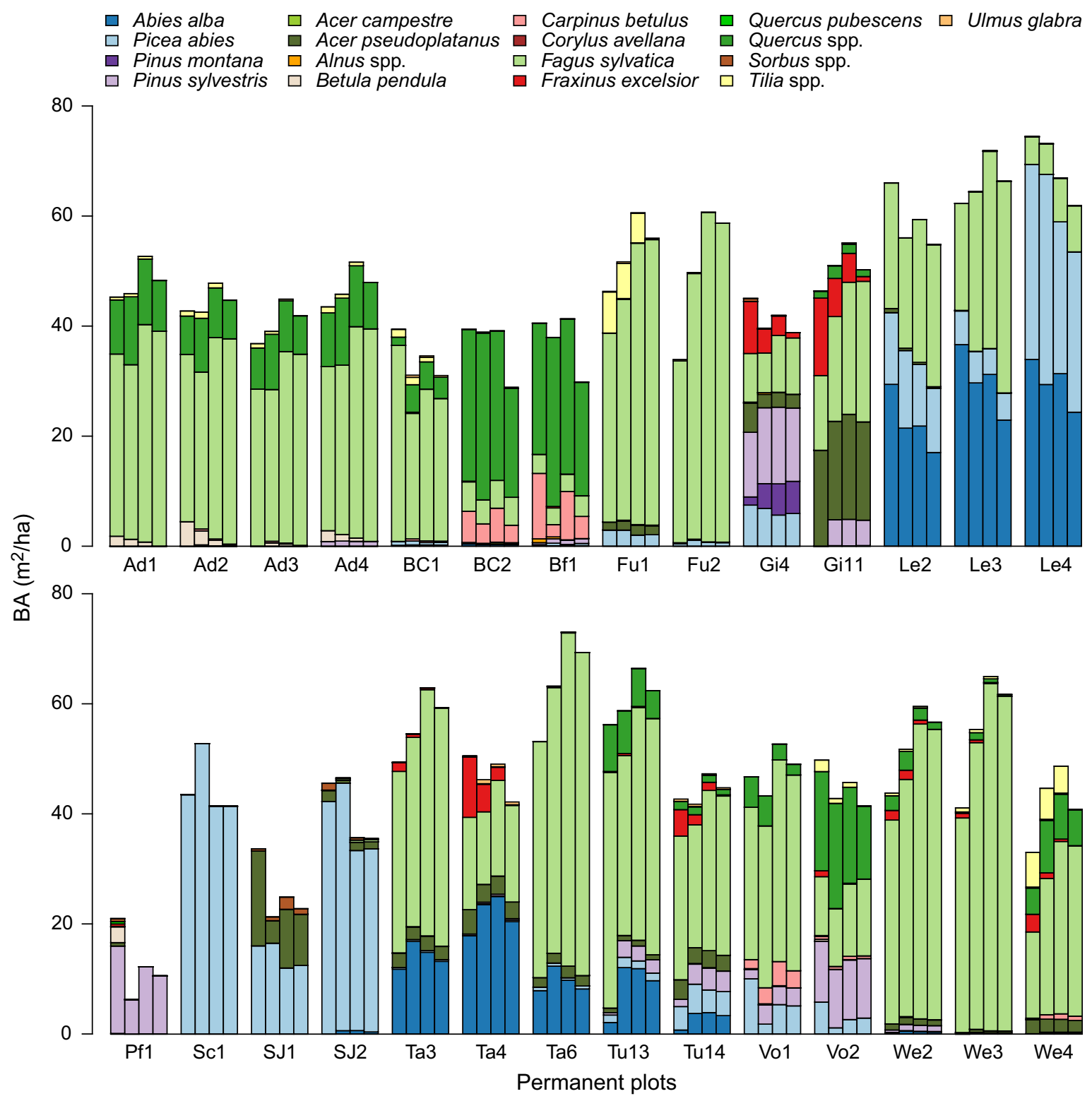

FIG. 2. Species-specific basal area (BA) observed (left-most bar for each plot; from inventory data) and simulated by the three model versions of ForClim (from left to right: ForClim 3.3, ForClim IM_mean, ForClim IM_sd) for each permanent plot at the last inventory. The acronyms of the permanent plots and the years of the last inventories are available in Appendix S1: Table S2.

species was negligible. This is in contrast to ForClim 3.3 and expected PNV under these conditions (Bugmann and Solomon 2000). The consideration of uncertainty in model parameters (IM_sd) reduced BA of Carpinus betulus and increased the presence of Picea abies but did not change the strong prevalence of Fagus sylvatica.

In contrast to expectations and outputs from ForClim 3.3 (Rasche et al. 2012), PNV in Sion simulated by ForClim IM_mean and IM_sd was not dominated by Pinus sylvestris but by Pinus mugo, and BA was comparably low. In addition, simulations of ForClim IM_mean resulted in an unexpected large presence of Acer campestre. The simulated biomass of Picea abies in Davos was lower than expected and suggested by ForClim 3.3, in particular for $\mathrm{DBH}>115 \mathrm{~cm}$.

\section{Discussion}

The development of new inventory-based mortality models provided novel insights with respect to (1) speciesspecific differences of mortality patterns, (2) potential advances of growth-based mortality models that include climate and stand characteristics, and (3) the suitability of empirical mortality models for implementation in DVMs. 
TABLE 4. Species-specific root mean square error (RMSE, $\mathrm{m}^{2} /$ ha or $\mathrm{ha}^{-1}$, respectively) and relative bias (rbias, \%) of BA and $\mathrm{N}_{\text {dead }}$ simulated by the three ForClim versions: latest model version (3.3), ForClim with new inventory-based mortality models using mean parameter estimates (IM_mean), and using randomly sampled parameters (IM_sd).

\begin{tabular}{|c|c|c|c|c|c|c|c|c|c|c|c|c|}
\hline \multirow[b]{3}{*}{ Species } & \multicolumn{6}{|c|}{ Basal area (BA) } & \multicolumn{6}{|c|}{ Number of dead stems $\left(N_{\text {dead }}\right)$} \\
\hline & \multicolumn{2}{|c|}{3.3} & \multicolumn{2}{|c|}{ IM_mean } & \multicolumn{2}{|c|}{ IM_sd } & \multicolumn{2}{|c|}{3.3} & \multicolumn{2}{|c|}{ IM_mean } & \multicolumn{2}{|c|}{ IM_sd } \\
\hline & RMSE & rbias & RMSE & rbias & RMSE & rbias & RMSE & rbias & RMSE & rbias & RMSE & rbias \\
\hline Abies alba & 4.6 & 7.2 & 4.2 & 7.6 & 5.8 & -14.3 & 4.0 & -44.0 & 4.9 & -56.3 & 3.1 & -33.9 \\
\hline Acer campestre & 0.1 & 241.5 & 0.1 & 311.7 & 0.0 & 148.8 & 0.1 & 33.7 & 0.2 & -48.2 & 0.1 & 40.0 \\
\hline Acer pseudoplatanus & 3.2 & -31.2 & 1.8 & -16.0 & 2.0 & -23.5 & 1.3 & -24.2 & 1.2 & -32.9 & 0.9 & -16.0 \\
\hline Alnus spp. & 0.3 & -2.7 & 0.5 & -88.6 & 0.5 & -97.2 & 0.6 & 2.0 & 0.2 & -8.1 & 0.2 & -10.4 \\
\hline Betula pendula & 1.4 & -50.1 & 1.8 & -74.1 & 2.2 & -99.0 & 1.5 & -19.4 & 1.5 & -16.3 & 1.6 & -12.5 \\
\hline Carpinus betulus & 3.0 & -43.1 & 1.3 & 9.3 & 2.5 & -38.2 & 1.1 & 29.0 & 1.3 & -37.9 & 1.4 & 26.3 \\
\hline Corylus avellana & 0.1 & -94.4 & 0.1 & -94.3 & 0.1 & -97.8 & 0.6 & -30.4 & 0.6 & -31.9 & 0.6 & -28.6 \\
\hline Fagus sylvatica & 6.4 & 5.7 & 11.5 & 33.1 & 11.2 & 32.5 & 3.0 & -24.3 & 5.2 & -62.5 & 4.9 & -58.3 \\
\hline Fraxinus excelsior & 2.8 & -52.1 & 3.6 & -69.2 & 5.0 & -95.1 & 1.0 & -25.7 & 0.9 & -0.5 & 1.4 & 44.0 \\
\hline Picea abies & 3.0 & 2.5 & 3.2 & -19.7 & 2.9 & -17.4 & 1.6 & -41.1 & 1.4 & -33.6 & 1.4 & -34.6 \\
\hline Pinus mugo & 2.1 & 171.9 & 3.0 & 240.2 & 3.1 & 251.0 & 3.1 & -61.8 & 3.7 & -74.0 & 3.7 & -74.2 \\
\hline Pinus sylvestris & 3.4 & 10.5 & 2.2 & 24.3 & 2.3 & 17.7 & 0.5 & -23.2 & 0.6 & -30.2 & 0.5 & -24.9 \\
\hline Quercus pubescens & 0.4 & -95.9 & 0.4 & -100.0 & 0.4 & -100.0 & 0.1 & -22.8 & 0.0 & -21.0 & 0.0 & -21.0 \\
\hline Quercus spp. & 2.7 & 24.3 & 2.0 & 10.3 & 2.8 & -17.7 & 1.7 & -66.3 & 1.0 & -38.0 & 0.4 & -4.9 \\
\hline Sorbus spp. & 0.3 & -53.1 & 0.5 & 11.4 & 0.4 & -58.7 & 0.4 & -18.4 & 0.7 & -36.1 & 0.4 & -18.3 \\
\hline Tilia spp. & 0.5 & -17.6 & 0.8 & -32.2 & 2.7 & -99.2 & 0.4 & -45.5 & 0.3 & -16.5 & 1.4 & 132.0 \\
\hline Ulmus glabra & 0.4 & 262.8 & 0.2 & 122.5 & 0.3 & 172.5 & 0.1 & -36.8 & 0.1 & -30.6 & 0.1 & 2.1 \\
\hline $\begin{array}{l}\text { Number of } \\
\text { species with } \\
\text { best performance }\end{array}$ & 9 & 10 & 7 & 6 & 1 & 1 & 7 & 5 & 4 & 4 & 9 & 10 \\
\hline
\end{tabular}

Notes: Results are shown for the last inventory of every permanent plot. For each species and variable of interest, the lowest RMSE and the rbias closest to zero were highlighted in bold. Trees with DBH $<4 \mathrm{~cm}$ were not considered.

\section{Species-specific patterns of mortality}

Tree mortality over DBH and relBAI was reverse J-shaped for nearly all species in our study. This is congruent with ecological theory of stress and vigor (Waring 1987), which suggests that individuals with restricted access to resources, i.e., those that have a small rooting and crown system (small trees; Harcombe 1987), and individuals that show reduced vitality (slow-growing trees; cf. Manion 1981, Stephenson et al. 2011), are exposed to higher stress and thus usually have a higher probability to die.

This general relationship between DBH, relBAI, and mortality is modified by species-specific traits that are related to life history strategies (cf. Fig. 4; Grime 1977, Brzeziecki and Kienast 1994). Specifically, species that can reach high age show lower mortality rates than typical pioneers. In addition, species with high shade tolerance are expected to have a good ability to survive in the subcanopy (Givnish 1988), i.e., when being small, and to resist low-growth periods (cf. storage hypothesis; Valladares and Niinemets 2008). Conversely, less shade-tolerant species are more likely to show increased mortality at low DBH and relBAI and thus a pronounced effect of size and growth on mortality (Kobe and Coates 1997). The four patterns that we identified for the influences of size and growth on mortality represent different expressions of these two traits, as discussed in the following.
The first group features low overall mortality and weak impacts of DBH and relBAI. It is dominated by relatively long-lived species with high shade tolerance (cf. Bugmann 1994 for specifications of maximum age and shade tolerance). While this applies to Abies alba, Fagus sylvatica, Picea abies, and Tilia cordata, the lifespan of Ulmus glabra is shorter, and thus the overall mortality rate we found appears low. However, the model for Ulmus glabra had only low discriminative ability, and thus this pattern is not necessarily reliable. In turn, Cornus mas and Pinus mugo are less shade-tolerant than the other species in this group, and the influences of DBH and relBAI arising from their models appear rather weak. Bearing in mind the shrubby shape and small size of Cornus mas, a maximum age of $300 \mathrm{yr}$ can be regarded as long living (San-Miguel-Ayanz et al. 2016). When taking into account the narrow DBH range of this species covered in the data, this may have led to weaker effects of DBH and relBAI than expected from species attributes. In contrast, Pinus mugo may not feature particularly high mortality rates for small and slow-growing trees due to its occurrence in relatively open stands under quite stressful conditions with respect to water and nutrient availability (Ellenberg 2009, Brang et al. 2014). As more competitive species are missing in these stands, the mortality patterns of Pinus mugo do not indicate high shade tolerance, but rather high tolerance of drought and lack of nutrients. 


\section{Expected Potential Natural Vegetation (PNV)}

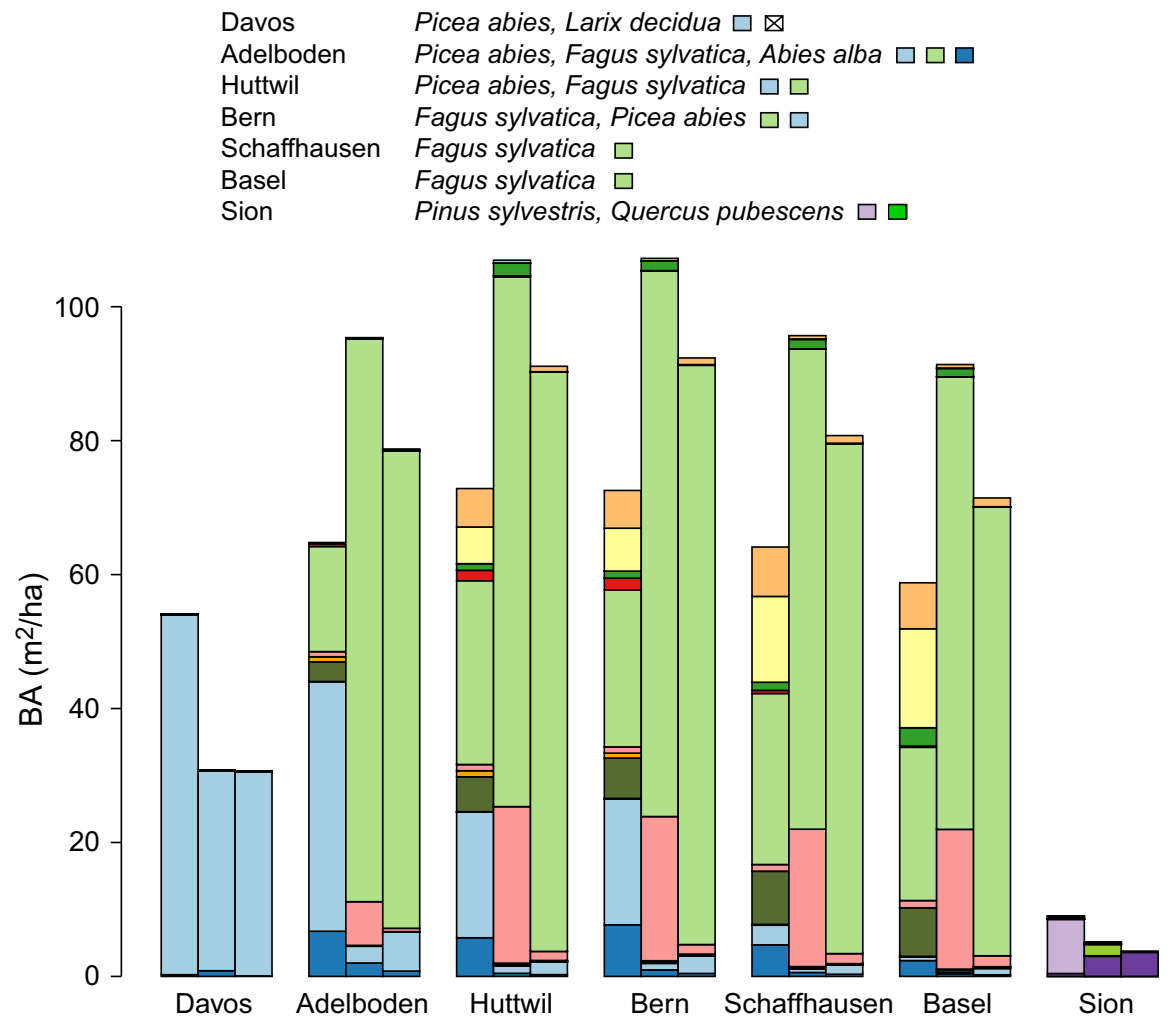

FIG. 3. Potential Natural Vegetation (PNV, BA per species) simulated along the Swiss environmental gradient at the end of a 1,500-yr run using ForClim 3.3 (left bar for each plot), ForClim IM_mean (middle bar), and ForClim IM_sd (right bar). Expectations of PNV are given according to Rasche et al. (2012). For the color codes of the less abundant species, refer to Fig. 2. Note that Larix decidua Mill. was not simulated in ForClim since no empirical mortality model could be fitted for this species.

In contrast, high overall mortality was identified for the second group that consists mainly of short-living pioneers, i.e., Alnus incana, Betula pendula, Corylus avellana, and Sorbus aria. The high mortality of slow-growing trees of these species is due to their low shade tolerance (for similar patterns cf. Wunder et al. 2008, Moustakas and Evans 2015). Given their low competitiveness, even large trees of these species experience high mortality risk (Brzeziecki and Kienast 1994).

Species of the third group show a similarly strong influence of relBAI on mortality, as Pinus sylvestris, Quercus pubescens, and Quercus spp. feature low shade tolerance as well. However, due to a higher maximum age, more large trees survive compared to the second group. In contrast, Acer pseudoplatanus is typically considered a shadetolerant species, and its seedlings achieve high survival and low but sustained growth under low light conditions (Ammer 1996). Nevertheless, shade tolerance considerably decreases when Acer seedlings become taller, which may explain why mortality decreased strongly with size and growth for this species (Hein et al. 2008).

The fourth group of Acer campestre, Carpinus betulus, and Fraxinus excelsior is characterized by medium life expectancy and medium to high shade tolerance. This is reflected in mortality patterns with average mortality effects of tree size and growth, which bridge between the other groups.

In contrast to the often proposed U-shaped mortality over tree size (Buchman et al. 1983, Lorimer and Frelich 1984), we did not find any evidence of a positive quadratic term for DBH in the models. This agrees with the results of Ruiz-Benito et al. (2013) and a recent assessment of inventory-based mortality models that revealed U-shaped mortality in four out of 58 cases only (Hülsmann et al. 2017). Higher background mortality of large trees is typically associated with a number of additional mortality agents such as insect attacks, drought, rot, or mechanical instability (Franklin et al. 1987, Das et al. 2016, Grote et al. 2016). In the forest reserves studied here, the lack of U-shaped mortality is most likely related to the relatively short time without forest management (approximately $60 \mathrm{yr}$, with the exception of $>200 \mathrm{yr}$ in Derborence and Scatlè; cf. Heiri et al. 2011, Meyer and Schmidt 2011). Consequently, a large population of big trees that would show the right tail of the U-shaped mortality is not present yet, in contrast to 


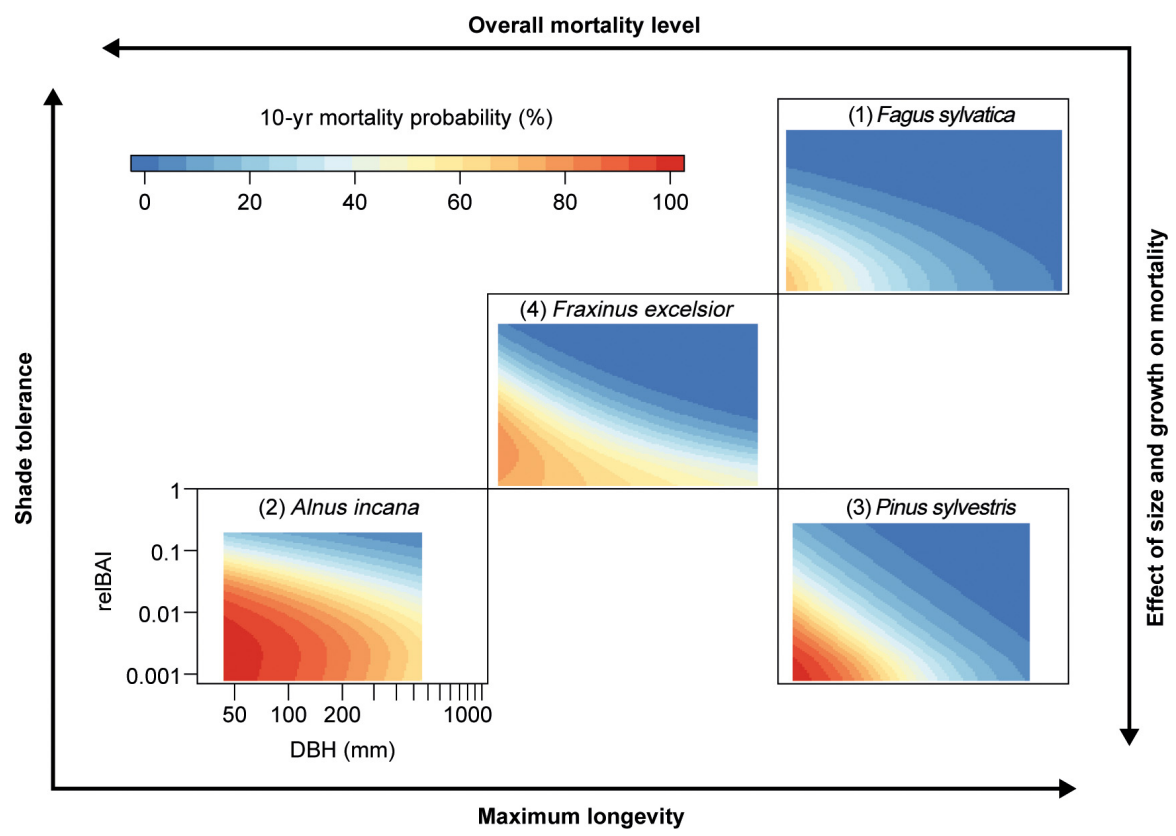

FIG. 4. Influence of maximum longevity and shade tolerance on mortality patterns. For each group, mortality for one example species is shown as a function of tree size (DBH) and growth (relBAI). Species that can reach high age show lower mortality rates than typical pioneers. In addition, species with high shade tolerance are expected to have a good ability to survive in the sub-canopy, i.e., when being small, and to resist low-growth periods. Conversely, less shade-tolerant species are more likely to show increased mortality at low DBH and relBAI and thus a pronounced effect of size and growth on mortality. Axes have the same scales as in Fig. 1.

true old-growth forests (Hülsmann et al. 2016; cf. Appendix S3 for an extended discussion on U-shaped mortality over tree size and growth).

\section{Climate and stand influences on mortality}

The infrequency of additional covariates for climate or stand properties in the final models does not necessarily disprove any direct long- or short-term environmental effects on mortality. Rather, this suggests that they are considered, at least to a large degree, via tree size and growth. Our study provides ample evidence across a large number of tree species that size (DBH) and growth (relBAI) sufficiently capture the influences of climatic and stand conditions on mortality probability, and tree size and growth can thus be used as integrative indicators of vitality (cf. Dobbertin 2005). In a previous study, we showed that not only precipitation and temperature but also a large variety of drought indices did not substantially improve mortality predictions for Fagus sylvatica (Hülsmann et al. 2016), a result supported by the findings of this study. Nevertheless, we were unable to test the influence of drought on mortality for all species due to limited data on soil water conditions. In addition, intense drought or bark beetle attacks may lead to sudden tree death (Peterken and Mountford 1996, Meddens et al. 2012) that cannot be elucidated with multi-annual remeasurements and would require a higher temporal resolution via annual inventories (e.g., Neuner et al.
2015) or dendrochronological data (e.g., Cailleret et al. 2017). Similarly, information on climate and stand properties was available at the level of the permanent plots only rather than for the local tree neighborhood, which may have impeded the identification of such effects on the mortality probability of individual trees.

Species that had additional covariates in the final model belong to different groups with respect to mortality patterns as a function of $\mathrm{DBH}$ and relBAI, and thus feature different life history strategies. In addition, these models included different covariates and effect directions (cf. influence of precipitation). Accordingly, the covariates do not reflect universal but rather species-specific environmental influences that may additionally depend on the available data set, as discussed in more detail in Appendix S3. Finally, none of the covariates interacted with relBAI, suggesting that the growth influence on mortality is constant across different environments.

Although we restricted our analysis to species with a minimum data coverage of 20 trees per plot and at least 10 permanent plots, the results indicate that the estimation of environmental effects on mortality critically depends on sufficiently wide and well supported environmental gradients. Otherwise, questionable effects (Pinus mugo and Quercus pubescens, cf. Appendix S3) are likely to occur. In turn, this may have prevented additional covariates to be retained in the models of other species, because many reserves are near the center of a species' range. Thus they do not encompass marginal populations with truly 
extreme conditions, which however is key for establishing the relationship between environmental effects and ecological processes.

\section{Suitability of empirical mortality models for incorporation in DVMs}

Calibration performance.-Mortality models for implementation in DVMs need to predict accurate mortality rates (Bircher et al. 2015, Cailleret et al. 2016). We therefore reported the relative variation in prediction accuracy between inventories ( $\left.\mathrm{rmad} p_{\text {bias }}\right)$, revealing considerable differences between species. On the one hand, the high accuracy in predicting mortality rates was often related to homogeneity of the underlying data (few permanent plots from one reserve only, cf. Cornus mas). The mortality model for this species is thus not necessarily better than the others, but it was fitted to rather homogeneous stand and site conditions. On the other hand, low rmad $p_{\text {bias }}$ values were identified for three models that included additional covariates (Alnus incana, Corylus avellana, and Quercus pubescens). Thus, the covariates improved the representation of variability in mortality between inventories in these data sets. Nevertheless, prediction accuracy was considerably lower for other species, even if their model included a climate or stand characteristic (e.g., Picea abies). This means that observed and predicted mortality rates deviated considerably for several species and that the models under- or overestimated annual mortality by up to $2.7 \%$ (quantified as the absolute value mad $p_{\text {bias }}$; cf. Table 3, Alnus incana) when applied in the calibration domain.

These findings confirm that the mortality process is highly variable in space and time (cf. Hawkes 2000, Wunder 2007), and it remains challenging to explain this variability with climate and/or stand characteristics using inventory data with a low temporal resolution. After all, mortality processes are likely to always be subject to pronounced stochasticity due to the complexity of biological, mechanical and competitive influences on mortality (Allen et al. 2015, Anderegg et al. 2015). Thus, it may be exceedingly hard to include these processes in any mortality functions, even in the most "mechanistic" approaches (Meir et al. 2015). This suggests that more emphasis should be placed on the adequate representation of the uncertainty in parameter estimates of empirical-based mortality functions. Parameter combinations can be sampled within their confidence intervals in a stochastic way as we did here, but we acknowledge that an even more beneficial approach would be to consider the cross-correlations between parameter values, which can be quantified, e.g., using Bayesian methods (Hartig et al. 2012).

The differences in AUC between species and trees of different size and the related uncertainty must be considered when empirically based mortality models are used to simulate forest dynamics in DVMs. Nevertheless, low AUC is less crucial for the implementation of mortality functions in DVMs. Poor discriminative ability can be the result of mortality agents that impair the relationship between mortality and the predictors chosen, or it can be due to poor data sources. For example, the unsatisfactory discrimination of Ulmus glabra may be caused by the rapid decline in response to infection with Ophiostoma novo-ulmi (Dutch elm disease; Brasier 2000) or by the small sample size used to calibrate its mortality function (cf. Table 1). In turn, the poor discrimination between living and dead trees of Picea abies was most likely caused by the impacts of small-scale windthrow, wet snow, or insect attacks that often result in sudden death irrespective of tree growth (Svoboda et al. 2010).

In a previous study, AUC patterns over DBH provided novel insights into the mortality processes of Fagus sylvatica that are changing during a tree's lifetime (Hülsmann et al. 2016). Our results for a much extended set of species confirm that the models' discriminative ability is decreasing with tree size also for several other tree species. This supports the conclusion that competition, which disproportionally affects smaller trees (Das et al. 2016), is the dominant mortality process reflected in the models. As competition becomes lower with increasing size and other mortality agents gain importance (cf. Holzwarth et al. 2013), the discriminative ability of the models is reduced. This is supported by the finding that Cornus mas and Corylus avellana, which reach small DBH only, show an increase of AUC with size. However, models of other species also retained good discriminative ability for larger DBH, and except for Abies alba, all these species feature low shade tolerance. This suggests that in shade-intolerant species even large trees may die due to competition, or due to mortality agents affecting the same trees as competition, which confers mortality models a good discrimination also in large individuals.

Considering that the behavior of parsimonious empirical models based on tree size and growth was biologically meaningful for most species, and that their performance was quite high and not impacted by changes in the sampling design (as supported by crossvalidation), we propose that the mortality algorithms developed here are suitable for implementation and evaluation in DVMs. Since covariates for climate and stand were only rarely included and partly revealed ecologically questionable relationships, we only implemented models without environmental covariates in ForClim. This appears appropriate since, from the species concerned, only Picea abies and Quercus spp. are of importance in the simulated permanent plots.

Implementation of the inventory-based mortality models in ForClim.-Although the predictions of stand basal area and species composition based on the new ForClim versions were generally close to historical observations, their performance was lower than with ForClim 3.3, especially for two major tree species of Central Europe, Fagus sylvatica and Picea abies. In the long term, PNV could not be simulated adequately and showed a strong 
overestimation of Fagus sylvatica (and Carpinus betulus in case of ForClim IM_mean). This was much to the detriment of other species such as Picea abies or Tilia spp., whose growth was excessively reduced by low light availability. For Picea abies, the new empirical mortality formulations prevented trees with $\mathrm{DBH}>115 \mathrm{~cm}$, although Picea abies in old-growth, subalpine forests clearly can attain larger size (Hillgarter 1971). The simulation performance differed considerably among species, and poor results could be attributed to over- and underestimation of mortality rates for different tree sizes. Overall, the calibration performance of the inventory-based models was not necessarily a good predictor for the accuracy of the simulation of species-specific BA and $N_{\text {dead }}$ by ForClim.

Since growth is one of the main predictors of tree death, the parameters determining growth and survival are highly correlated (Bircher 2015). Hence differences between simulated and observed growth rates may partly explain differences between simulated and observed mortality rates. For instance, underestimated mortality rates of Fagus sylvatica, especially for trees with $\mathrm{DBH}<20 \mathrm{~cm}$, can be related to the overestimation of their simulated relative growth rates (see Appendix S1: Fig. S4). This systematic bias, which was also observed for Picea abies and Pinus sylvestris (albeit to a lower extent), can originate from multiple sources such as an inaccurate simulation of the effect of light availability or crown size on tree growth (Mina et al. 2015), difficulties in the growth equation that is used to simulate diameter increment (Moore 1989), or an unrealistic stand initialization in ForClim. Because of the random and even allocation of trees to an initial set of patches, which are then replicated to obtain 200 patches per simulation, the diversity in stand structure among patches at initialization is much lower than observed in the field. Similarly, as ForClim does not track tree position, the variability in competition intensity among trees may not be represented accurately enough.

Mortality predictions appeared particularly problematic for trees with $\mathrm{DBH}<10 \mathrm{~cm}$ and $>60 \mathrm{~cm}$ (cf. Larocque et al. 2011, Bircher et al. 2015). These difficulties are likely to result from extrapolation since the inventory data set is truncated for small DBH (calipering limit of 4 and $7 \mathrm{~cm}$, cf. Material and Methods), and contains fewer large trees than would occur in true old-growth forests. In addition, different agents affect the mortality of large individuals that may not be reflected well in the empirical mortality models (cf. AUC patterns over DBH). When implemented in DVMs, U-shaped DBH-mortality functions may be preferable over J-shaped functions to avoid the persistence of very large trees in long-term simulations, as observed here with Fagus sylvatica. To implement this U-shape in spite of the poor data availability of large trees, semi-empirical models that combine empirically derived formulations with theoretical adjustments (e.g., assuming a maximum DBH; Manusch et al. 2012) may be required. In turn, mortality formulations for small trees should be refined using regeneration surveys, inventories without calipering limit, stem cross- sections, or experiments (Wernsdörfer et al. 2008, Canham and Murphy 2016, Evans and Moustakas 2016). At the same time, the representation of tree regeneration and establishment that similarly suffer from a poor empirical foundation could be improved by extending mortality models to seedlings (Wehrli et al. 2007).

Due to the non-linearity between the predictors and the mortality probability (cf. logit link function), which is then transposed into a binary variable (tree death or survival) based on a stochastic approach (see Bircher et al. 2015), accounting for uncertainty in model estimates typically increases mortality rates. Although this approach can reduce systematic underestimations of tree mortality rates and thus improve simulation accuracy (unpublished manuscript), it did not considerably increase mortality rates of Fagus sylvatica. This may be related to the large number of records in the calibration data set of this species, which resulted in low parameter uncertainty. Nevertheless, accounting for uncertainty appears promising for species for which inventory sample size is small and diversity in mortality patterns among sites and individuals is high, and we therefore advocate evaluating this approach further (Cressie et al. 2009).

\section{Conclusion}

We identified dominantly reverse J-shaped mortality over tree size and growth across 18 tree species, using inventory data from forest reserves. These patterns reflect the indirect influences of resource availability and tree vitality on mortality but rebut the assumption of a general substantial instability of large trees. Furthermore, the patterns confirmed that size- and growthdependent mortality relationships are modulated by species-specific attributes.

If species-specific models are unfeasible due to data limitations, we propose that maximum longevity and shade tolerance should be used for the classification of tree species into PFTs to predict mortality, but we think that this approach should be tested further (cf. Bircher 2015). Species with intermediate behavior may be misrepresented if the continuous traits of lifespan and shade tolerance are used to build categories, and species are accordingly assigned to the resulting groups. The same applies if additional attributes modify the mortality patterns (e.g., Cornus mas, Pinus mugo, Ulmus glabra). Therefore, species-specific mortality models should be favored over parameterizations for PFTs, so as to obtain DVMs with an appropriate representation of demographic diversity.

Based on our analysis of the role of environmental covariates in mortality models, we conclude that tree size and growth alone are well suited to predict tree death of most species. These models consider environmental effects indirectly, i.e., via integrative indicators of tree vitality such as size and growth. Nevertheless, the climatic sensitivity of growth-based mortality functions should be verified using data with higher temporal resolution, followed by an in-depth evaluation in DVMs. 
Additionally, the predictive ability of tree size and growth is restricted to mortality associated with particular size and growth levels. Thus, processes such as shortterm intense drought, mechanical damage or insect attacks may not be fully reflected by these models (Larson and Franklin 2010, Cailleret et al. 2017). Finally, we emphasize that caution is required when additional covariates are considered in mortality models. Their effects may appear erratically if the environmental gradient underlying the observational data is insufficient. Applying such models means leaving the domain of calibration, which can result in unwarranted extrapolation and misleading inference (Hawkes 2000, Woolley et al. 2012, Kuhn and Johnson 2013). Therefore, the selection of environmental covariates in mortality models should be based on the principle of parsimony (Sims et al. 2009, Burkhart and Tomé 2012).

When incorporated in a DVM, the new inventorybased mortality models successfully simulated shortterm dynamics but showed weaknesses in simulating stand structure and species composition in the long term. These difficulties were the result of feedbacks between simulated growth and mortality as well as of extrapolation to small and very large trees. Thus, both, growth and mortality processes and their species-specific differences should be revisited jointly, with a particular focus on small and very large trees, e.g., using a Bayesian calibration approach (Hartig et al. 2012, Bircher 2015). Yet, we conclude that inventory-based mortality formulations can replace theoretical concepts of mortality in DVMs since they provide species-specific mortality relationships that are not based on single parameters such as maximum age and growth but on empirical relationships over a tree's lifetime.

The benefit of empirical mortality models in DVMs and the accuracy of long-term predictions of PNV could be enhanced further if disturbance-related mortality was incorporated more explicitly (Seidl et al. 2011, Temperli et al. 2013). To this end, the identification and quantification of the respective mortality agents under field conditions using at least annual mortality assessments is necessary (Holzwarth et al. 2013, Lutz 2015), which is usually not done in data sets with high spatial coverage (but see Das et al. 2016).

Considering the need to better simulate forest ecosystems and their response to climate change, implementing accurate mortality functions in DVMs is of utmost importance due to their cascading effects on recruitment, growth and mortality of the remaining trees, and consequently on forest structure and species composition. We strongly recommend inventory-based mortality formulations, in particular those that consider speciesspecific differences, as a promising element to enhance the robustness and reliability of DVM projections.

\section{ACKNOWLEDGMENTS}

This study relies on the enormous efforts invested in the monitoring of Swiss and German forest reserves since the 1950s. The monitoring in the Swiss reserves obtains significant funding by the Federal Office of the Environment. We would like to express our gratitude to Peter Meyer who kindly provided the data from Lower Saxony. In addition, we like to thank Nicolas Bircher and Johannes Sutmöller for processing the climate data and Andreas Ruckstuhl and Jürgen Zell for valuable statistical discussions. This study was funded by the Swiss National Science Foundation project "Predicting growth-dependent tree mortality: a key challenge for population ecology" (grant no. 31003A_140968).

\section{Literature Cited}

Adams, H. D., A. P. Williams, C. Xu, S. A. Rauscher, X. Jiang, and N. G. McDowell. 2013. Empirical and process-based approaches to climate-induced forest mortality models. Frontiers in Plant Science 4:438.

Allen, C. D., et al. 2010. A global overview of drought and heatinduced tree mortality reveals emerging climate change risks for forests. Forest Ecology and Management 259:660-684.

Allen, C. D., D. D. Breshears, and N. G. McDowell. 2015. On underestimation of global vulnerability to tree mortality and forest die-off from hotter drought in the Anthropocene. Ecosphere 6:art129.

Ammer, C. 1996. Konkurrenz um Licht. Zur Entwicklung der Naturverjüngung im Bergmischwald. Forstliche Forschungsberichte München Nr. 158, München, Germany.

Anderegg, W. R., et al. 2015. Tree mortality from drought, insects, and their interactions in a changing climate. New Phytologist 208:674-683.

Bigler, C., and H. Bugmann. 2004. Predicting the time of tree death using dendrochronological data. Ecological Applications 14:902-914.

Bircher, N. 2015. To die or not to die: Forest dynamics in Switzerland under climate change. PhD Thesis. ETH Zürich, Zürich, Switzerland.

Bircher, N., M. Cailleret, and H. Bugmann. 2015. The agony of choice: different empirical mortality models lead to sharply different future forest dynamics. Ecological Applications 25: 1303-1318.

Brang, P., H. Bugmann, and C. Heiri. 2011. Waldreservate. 50 Jahre natürliche Waldentwicklung in der Schweiz. Haupt, Bern, Stuttgart, Wien. Birmensdorf, Eidg. Forschungsanstalt WSL. ETH Zürich, Zürich, Switzerland.

Brang, P., H. Bugmann, R. Haller, C. Heiri, and M. Huber. 2014. Der lange Weg zur Waldwildnis. Pages 212-233 in B. Baur and T. Scheurer, editors. 100 Jahre Forschung im Schweizerischen Nationalpark. Haupt, Bern, Switzerland.

Brasier, C. M. 2000. Intercontinental spread and continuing evolution of the Dutch elm disease pathogens. Pages 61-72 in C. P. Dunn, editor. The elms: breeding, conservation, and disease management. Springer, Boston, Massachusetts, USA.

Bravo-Oviedo, A., H. Sterba, M. Del Río, and F. Bravo. 2006. Competition-induced mortality for Mediterranean Pinus pinaster Ait. and P. sylvestris L. Forest Ecology and Management 222:88-98.

Breiman, L., J. Friedman, C. J. Stone, and R. A. Olshen. 1984. Classification and regression trees. Wadsworth, Belmont, California, USA.

Brzeziecki, B., and F. Kienast. 1994. Classifying the life-history strategies of trees on the basis of the Grimian model. Forest Ecology and Management 69:167-187.

Buchman, R. G., S. P. Pederson, and N. R. Walters. 1983. A tree survival model with application to species of the great-lakes region. Canadian Journal of Forest Research 13:601-608.

Bugmann, H. 1994. On the ecology of mountainous forests in a changing climate: a simulation study. PhD Thesis. ETH Zurich, Zurich, Switzerland. 
Bugmann, H. 1996a. Functional types of trees in temperate and boreal forests: Classification and testing. Journal of Vegetation Science 7:359-370.

Bugmann, H. 1996b. A simplified forest model to study species composition along climate gradients. Ecology 77:2055-2074.

Bugmann, H. 2001. A review of forest gap models. Climatic Change 51:259-305.

Bugmann, H. K. M., and A. M. Solomon. 2000. Explaining forest composition and biomass across multiple biogeographical regions. Ecological Applications 10:95-114.

Burkhart, H. E., and M. Tomé. 2012. Modeling forest trees and stands. First edition. Springer Netherlands, Dordrecht, The Netherlands.

Cailleret, M., et al. 2016. Toward a common methodology for developing logistic tree mortality models based on ring-width data. Ecological Applications 26:1827-1841.

Cailleret, M., et al. 2017. A synthesis of radial growth patterns preceding tree mortality. Global Change Biology 23:16751690.

Canham, C. D., and L. Murphy. 2016. The demography of tree species response to climate: Seedling recruitment and survival. Ecosphere 7:e01424.

Condés, S., and M. Del Río. 2015. Climate modifies tree interactions in terms of basal area growth and mortality in monospecific and mixed Fagus sylvatica and Pinus sylvestris forests. European Journal of Forest Research 134:1095-1108.

Cressie, N., C. A. Calder, J. S. Clark, J. M. V. Hoef, and C. K. Wikle. 2009. Accounting for uncertainty in ecological analysis: the strengths and limitations of hierarchical statistical modeling. Ecological Applications 19:553-570.

Das, A. J., N. L. Stephenson, and K. P. Davis. 2016. Why do trees die? Characterizing the drivers of background tree mortality. Ecology 97:2616-2627.

De Groot, R. S., M. A. Wilson, and R. M. J. Boumans. 2002. A typology for the classification, description and valuation of ecosystem functions, goods and services. Ecological Economics 41:393-408.

Didion, M., A. D. Kupferschmid, A. Wolf, and H. Bugmann. 2011. Ungulate herbivory modifies the effects of climate change on mountain forests. Climatic Change 109:647-669.

Dietze, M. C., and P. R. Moorcroft. 2011. Tree mortality in the eastern and central United States: Patterns and drivers. Global Change Biology 17:3312-3326.

Dobbertin, M. 2005. Tree growth as indicator of tree vitality and of tree reaction to environmental stress: a review. European Journal of Forest Research 124:319-333.

Eid, T., and E. Tuhus. 2001. Models for individual tree mortality in Norway. Forest Ecology and Management 154:69-84.

Ellenberg, H. 2009. Vegetation ecology of Central Europe. Fourth edition. Cambridge University Press, Cambridge, UK.

Evans, M. R., and A. Moustakas. 2016. A comparison between data requirements and availability for calibrating predictive ecological models for lowland UK woodlands: learning new tricks from old trees. Ecology and Evolution 6:4812-4822.

Franklin, J. F., H. H. Shugart, and M. E. Harmon. 1987. Tree death as an ecological process: the causes, consequences and variability of tree mortality. BioScience 37:550-556.

Friend, A. D., et al. 2014. Carbon residence time dominates uncertainty in terrestrial vegetation responses to future climate and atmospheric $\mathrm{CO}_{2}$. Proceedings of the National Academy of Sciences USA 111:3280-3285.

Gillner, S., N. Rüger, A. Roloff, and U. Berger. 2013. Low relative growth rates predict future mortality of common beech (Fagus sylvatica L.). Forest Ecology and Management 302:372-378.
Givnish, T. J. 1988. Adaptation to sun and shade: a wholeplant perspective. Australian Journal of Plant Physiology 15:63-92.

Grime, J. P. 1977. Evidence for the existence of three primary strategies in plants and its relevance to ecological and evolutionary theory. American Naturalist 111:1169-1194.

Grote, R., A. Gessler, R. Hommel, W. Poschenrieder, and E. Priesack. 2016. Importance of tree height and social position for drought-related stress on tree growth and mortality. Trees 30:1467-1482.

Harcombe, P. A. 1987. Tree life tables. BioScience 37:557-568.

Harrell, F. E. 2015. Regression modeling strategies: with applications to linear models, logistic and ordinal regression, and survival analysis. Second edition. Springer International Publishing, Cham, Switzerland.

Hartig, F., J. Dyke, T. Hickler, S. I. Higgins, R. B. O'Hara, S. Scheiter, and A. Huth. 2012. Connecting dynamic vegetation models to data - an inverse perspective. Journal of Biogeography 39:2240-2252.

Hasenauer, H., editor. 2006. Sustainable forest management: Growth models for Europe. Springer, Berlin Heidelberg, Germany.

Hastie, T., R. Tibshirani, and J. Friedman. 2001. The elements of statistical learning: data mining, inference, and prediction. Springer, New York, New York, USA.

Hawkes, C. 2000. Woody plant mortality algorithms: description, problems and progress. Ecological Modelling 126:225248.

Hein, S., C. Collet, C. Ammer, N. L. Goff, J. P. Skovsgaard, and P. Savill. 2008. A review of growth and stand dynamics of Acer pseudoplatanus L. in Europe: implications for silviculture. Forestry 82:361-385.

Heiri, C., P. Brang, B. Commarmot, J. F. Matter, and H. Bugmann. 2011. Walddynamik in Schweizer Naturwaldreservaten: Kennzahlen und Trends. Pages 74-89 in P. Brang, C. Heiri, and H. Bugmann, editors. Waldreservate. 50 Jahre natürliche Waldentwicklung in der Schweiz. Haupt, Bern, Stuttgart, Wien, Birmensdorf, Eidg. Forschungsanstalt WSL, ETH Zürich, Zürich, Switzerland

Hillgarter, F.-W. 1971. Waldbauliche und ertragskundliche Untersuchungen im subalpinen Fichtenurwald Scatlé/Brigels. PhD Thesis. ETH Zürich, Zürich, Switzerland.

Holzwarth, F., A. Kahl, J. Bauhus, and C. Wirth. 2013. Many ways to die - partitioning tree mortality dynamics in a nearnatural mixed deciduous forest. Journal of Ecology 101:220 230 .

Hosmer, D. W., and S. Lemeshow. 2000. Applied logistic regression. John Wiley \& Sons Inc, New York, New York, USA.

Hülsmann, L., H. Bugmann, B. Commarmot, P. Meyer, S. Zimmermann, and P. Brang. 2016. Does one model fit all? Patterns of beech mortality in natural forests of three European regions. Ecological Applications 26:2463-2477.

Hülsmann, L., H. Bugmann, and P. Brang. 2017. How to predict tree death from inventory data - Lessons from a systematic assessment of European tree mortality models. Canadian Journal of Forest Research 47:890-900.

Keane, R. E., M. Austin, C. Field, A. Huth, M. J. Lexer, D. Peters, A. Solomon, and P. Wyckoff. 2001. Tree mortality in gap models: Application to climate change. Climatic Change 51:509-540

Kobe, R. K., and K. D. Coates. 1997. Models of sapling mortality as a function of growth to characterize interspecific variation in shade tolerance of eight tree species of northwestern British Columbia. Canadian Journal of Forest Research 27:227-236. 
Kuhn, M., and K. Johnson. 2013. Applied predictive modeling. Springer, New York, New York, USA.

Larocque, G. R., L. Archambault, and C. Delisle. 2011. Development of the gap model ZELIG-CFS to predict the dynamics of North American mixed forest types with complex structures. Ecological Modelling 222:2570-2583.

Larson, A. J., and J. F. Franklin. 2010. The tree mortality regime in temperate old-growth coniferous forests: The role of physical damage. Canadian Journal of Forest Research 40:2091-2103.

Loehle, C., and D. LeBlanc. 1996. Model-based assessments of climate change effects on forests: a critical review. Ecological Modelling 90:1-31.

Lorimer, C. G., and L. E. Frelich. 1984. A simulation of equilibrium diameter distributions of sugar maple (Acer saccharum). Bulletin of the Torrey Botanical Club 111:193-199.

Lutz, J. A. 2015. The evolution of long-term data for forestry: Large temperate research plots in an era of global change. Northwest Science 89:255-269.

Manion, P. D. 1981. Tree disease concepts. Prentice-Hall, London, UK.

Manusch, C., H. Bugmann, C. Heiri, and A. Wolf. 2012. Tree mortality in dynamic vegetation models - A key feature for accurately simulating forest properties. Ecological Modelling 243:101-111.

McDowell, N. G., M. G. Ryan, M. J. B. Zeppel, and D. T. Tissue. 2013. Improving our knowledge of drought-induced forest mortality through experiments, observations, and modeling. New Phytologist 200:289-293.

Meddens, A. J. H., J. A. Hicke, and C. A. Ferguson. 2012. Spatiotemporal patterns of observed bark beetle-caused tree mortality in British Columbia and the western United States. Ecological Applications 22:1876-1891.

Meir, P., M. Mencuccini, and R. C. Dewar. 2015. Droughtrelated tree mortality: Addressing the gaps in understanding and prediction. New Phytologist 207:28-33.

Meyer, P., and M. Schmidt. 2011. Accumulation of dead wood in abandoned beech (Fagus sylvatica L.) forests in northwestern Germany. Forest Ecology and Management 261:342-352.

Meyer, P., A. Wevell von Krüger, R. Steffens, and W. Unkrig. 2006. Naturwälder in Niedersachsen, Schutz und Forschung - Band 1 (Tiefland). Nordwestdeutsche Forstliche Versuchsanstalt, Göttingen, Germany; Niedersächsische Landesforsten, Braunschweig, Germany.

Meyer, P., K. Lorenz, A. Mölder, R. Steffens, W. Schmidt, T. Kompa, and A. Wevell von Krüger. 2015. Naturwälder in Niedersachsen, Schutz und Forschung-Band 2 (Bergland). Leinebergland-Druck, Alfeld (Leine), Germany.

Millar, C. I., and N. L. Stephenson. 2015. Temperate forest health in an era of emerging megadisturbance. Science 349:823-826.

Mina, M., H. Bugmann, M. Klopcic, and M. Cailleret. 2015. Accurate modeling of harvesting is key for projecting future forest dynamics: a case study in the Slovenian mountains. Regional Environmental Change 17:49-64.

Monserud, R. A. 1976. Simulation of forest tree mortality. Forest Science 22:438-444.

Moore, A. D. 1989. On the maximum growth equation used in forest gap simulation models. Ecological Modelling 45:63-67.

Mosteller, F., and J. W. Tukey. 1977. Data analysis and regression: a second course in statistics. Addison-Wesley Publishing, Reading, Massachusetts, USA.

Moustakas, A., and M. R. Evans. 2015. Effects of growth rate, size, and light availability on tree survival across life stages: A demographic analysis accounting for missing values and small sample sizes. BMC Ecology 15:6.
Neuner, S., et al. 2015. Survival of Norway spruce remains higher in mixed stands under a dryer and warmer climate. Global Change Biology 21:935-946.

Peterken, G. F., and E. P. Mountford. 1996. Effects of drought on beech in Lady Park Wood, an unmanaged mixed deciduous woodland. Forestry 69:125-136.

Rasche, L., L. Fahse, A. Zingg, and H. Bugmann. 2012. Enhancing gap model accuracy by modeling dynamic height growth and dynamic maximum tree height. Ecological Modelling 232:133-143.

R Core Team. 2015. R statistical software. R Foundation for Statistical Computing, Vienna, Austria. www.r-project.org

Reyer, C., et al. 2015. Forest resilience and tipping points at different spatio-temporal scales: approaches and challenges. Journal of Ecology 103:5-15.

Rowland, L., et al. 2015. Death from drought in tropical forests is triggered by hydraulics not carbon starvation. Nature 528:119-122.

Ruiz-Benito, P., E. R. Lines, L. Gómez-Aparicio, M. A. Zavala, and D. A. Coomes. 2013. Patterns and drivers of tree mortality in Iberian forests: climatic effects are modified by competition. PLoS ONE 8:e56843.

Sala, A., F. Piper, and G. Hoch. 2010. Physiological mechanisms of drought-induced tree mortality are far from being resolved. New Phytologist 186:274-281.

San-Miguel-Ayanz, J., D. de Rigo, G. Caudullo, T. H. Durrant, and A. Mauri, editors. 2016. European atlas of forest tree species. Publication Office of the European Union, Luxembourg City, Luxembourg.

Seidl, R., et al. 2011. Modelling natural disturbances in forest ecosystems: a review. Ecological Modelling 222:903-924.

Sims, A., A. Kiviste, M. Hordo, D. Laarmann, and K. V. Gadow. 2009. Estimating tree survival: A study based on the Estonian forest research plots network. Annales Botanici Fennici 46:336-352.

Smith, B., I. C. Prentice, and M. T. Sykes. 2001. Representation of vegetation dynamics in the modelling of terrestrial ecosystems: Comparing two contrasting approaches within European climate space. Global Ecology and Biogeography 10:621-637.

Stahel, W. 2015. regr0: Building regression models. R package version 1.0-4/r46. URL: http://r-forge.r-project.org/projects/ regdevelop/

Steinkamp, J., T. Hickler, and D. Gibson. 2015. Is droughtinduced forest dieback globally increasing? Journal of Ecology 103:31-43.

Stephenson, N. L., P. J. Van Mantgem, A. G. Bunn, H. Bruner, M. E. Harmon, K. B. O'Connell, D. L. Urban, and J. F. Franklin. 2011. Causes and implications of the correlation between forest productivity and tree mortality rates. Ecological Monographs 81:527-555.

Steyerberg, E. W., A. J. Vickers, N. R. Cook, T. Gerds, M. Gonen, N. Obuchowski, M. J. Pencina, and M. W. Kattan. 2010. Assessing the performance of prediction models: a framework for traditional and novel measures. Epidemiology 21:128-138.

Svoboda, M., S. Fraver, P. Janda, R. Bače, and J. Zenáhlíková. 2010. Natural development and regeneration of a Central European montane spruce forest. Forest Ecology and Management 260:707-714.

Temperli, C., H. Bugmann, and C. Elkin. 2012. Adaptive management for competing forest goods and services under climate change. Ecological Applications 22:2065-2077.

Temperli, C., H. Bugmann, and C. Elkin. 2013. Cross-scale interactions among bark beetles, climate change, and wind disturbances: a landscape modeling approach. Ecological Monographs 83:383-402. 
Valladares, F., and Ü. Niinemets. 2008. Shade tolerance, a key plant feature of complex nature and consequences. Annual Review of Ecology, Evolution, and Systematics 39:237-257.

Van Mantgem, P. J., et al. 2009. Widespread increase of tree mortality rates in the Western United States. Science 323:521524.

Waring, R. H. 1987. Characteristics of trees predisposed to die. BioScience 37:569-574.

Wehrli, A., A. Zingg, H. Bugmann, and A. Huth. 2005. Using a forest patch model to predict the dynamics of stand structure in Swiss mountain forests. Forest Ecology and Management 205:149-167.

Wehrli, A., P. J. Weisberg, W. Schönenberger, P. Brang, and H. Bugmann. 2007. Improving the establishment submodel of a forest patch model to assess the long-term protective effect of mountain forests. European Journal of Forest Research 126:131-145.

Weiskittel, A. R., D. W. Hann, J. A. Kershaw, and J. K. Vanclay. 2011. Forest growth and yield modeling. John Wiley \& Sons, West Sussex, UK.

Wernsdörfer, H., V. Rossi, G. Cornu, S. Oddou-Muratorio, and S. Gourlet-Fleury. 2008. Impact of uncertainty in tree mortality on the predictions of a tropical forest dynamics model. Ecological Modelling 218:290-306.

Woolley, T., D. C. Shaw, L. M. Ganio, and S. Fitzgerald. 2012. A review of logistic regression models used to predict post-fire tree mortality of western North American conifers. International Journal of Wildland Fire 21:1-35.

Wullschleger, S. D., H. E. Epstein, E. O. Box, E. S. Euskirchen, S. Goswami, C. M. Iversen, J. Kattge, R. J. Norby, P. M. van Bodegom, and X. Xu. 2014. Plant functional types in Earth system models: past experiences and future directions for application of dynamic vegetation models in high-latitude ecosystems. Annals of Botany 114:1-16.

Wunder, J. 2007. Conceptual advancement and ecological applications of tree mortality models based on tree-ring and forest inventory data. PhD Thesis. ETH Zurich, Zurich, Switzerland.

Wunder, J., C. Bigler, B. Reineking, L. Fahse, and H. Bugmann. 2006. Optimisation of tree mortality models based on growth patterns. Ecological Modelling 197:196-206.

Wunder, J., B. Brzeziecki, H. Zybura, B. Reineking, C. Bigler, and H. Bugmann. 2008. Growth-mortality relationships as indicators of life-history strategies: A comparison of nine tree species in unmanaged European forests. Oikos 117:815-828.

Wyckoff, P. H., and J. S. Clark. 2002. The relationship between growth and mortality for seven co-occurring tree species in the southern Appalachian Mountains. Journal of Ecology 90:604-615.

Yang, Y., and S. Huang. 2013. A generalized mixed logistic model for predicting individual tree survival probability with unequal measurement intervals. Forest Science 59:177-187.

\section{SUPPORTING INFORMATION}

Additional supporting information may be found online at: http://onlinelibrary.wiley.com/doi/10.1002/eap.1668/full

Data Availability

Data available from the WSL EnviDat data portal: https://doi.org/10.16904/envidat.27 